\title{
From fAIrplay to climate wars: making climate change scenarios more dynamic, creative, and integrative
}

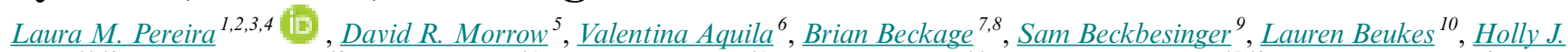 \\ ${\text { Buck }^{11,12}}^{\text {, Colin J. Carlson }}{ }^{13}, \underline{\text { Oliver Geden }}^{14}, \underline{\text { Andrew P. Jones }}^{15}, \underline{\text { David P. Keller }}^{16}, \underline{\text { Katharine J. Mach }}{ }^{17,18}$, Mohale Mashigo $^{9}, \underline{\text { Juan }}^{2,2}$ \\ B. Moreno-Cruz ${ }^{19}$, Daniele Visioni ${ }^{20}$, Simon Nicholson ${ }^{5}$ and Christopher H. Trisos ${ }^{21,22}$
}

\begin{abstract}
Understanding possible climate futures that include carbon dioxide removal (CDR) and solar radiation modification (SRM) requires thinking not just about staying within the remaining carbon budget, but also about politics and people. However, despite growing interest in CDR and SRM, scenarios focused on these potential responses to climate change tend to exclude feedbacks between social and climate systems (a criticism applicable to climate change scenarios more generally). We adapted the Manoa MashUp method to generate scenarios for CDR and SRM that were more integrative, creative, and dynamic. The method was modified to identify important branching points in which different choices in how to respond to climate change (feedbacks between climate and social dynamics) lead to a plurality of climate futures. An interdisciplinary group of participants imagined distant futures in which SRM or CDR develop into a major social-environmental force. Groups received other "seeds" of change, such as Universal Basic Income or China's Belt and Road Initiative, and surprises, such as permafrost collapse that grew to influence the course of events to 2100. Groups developed narratives describing pathways to the future and identified bifurcation points to generate families of branching scenarios. Four climate-social dynamics were identified: motivation to mitigate, moral hazard, social unrest, and trust in institutions. These dynamics could orient toward better or worse outcomes with SRM and CDR deployment (and mitigation and adaptation responses more generally) but are typically excluded from existing climate change scenarios. The importance of these dynamics could be tested through the inclusion of social-environmental feedbacks into integrated assessment models (IAM) exploring climate futures. We offer a step-by-step guide to the modified Manoa Mash-up method to generate more integrative, creative, and dynamic scenarios; reflect on broader implications of using this method for generating more dynamic scenarios for climate change research and policy; and provide examples of using the scenarios in climate policy communication, including a choose-your-own adventure game called Survive the Century (https://survivethecentury.net/), which was played by over 15,000 people in the first 2 weeks of launching.
\end{abstract}

Key Words: carbon dioxide removal; climate change; futures; geoengineering scenarios; science fiction; solar radiation management

\section{INTRODUCTION}

Scenarios play an important role in the crafting and shaping of thinking about how societies might experience and respond to climate change (O'Neill et al. 2020). Indeed, scenario generation is woven deeply into the science, modeling, and policy activities that render climate futures visible and tangible. This is because in the absence of observational data about the future, the production of coherent narratives is one of the most important tools available for enhancing our collective ability to imagine a diversity of future interactions between people and the environment (Nature 2018, Elsawah et al. 2020). However, the standard tools for scenario development tend to produce visions of the future that are overly linear and that shy away from explorations of social and political complexity (Pereira et al. 2021). To date, narrative storylines for climate change scenarios have tended to be developed by tight clusters of scientists concerned chiefly with the plausibility of particular futures, with a common focus on the translatability of narrative insights into climate modeling parameters (see O'Neill et al. 2017). Although these scenarios do not typically aim to predict the future, some critics have worried that these scenarios, including the shared socioeconomic pathways (SSP), embody a lack of creativity and are too managerial, making the future appear more knowable than it is (Hulme 2020). The COVID-19 pandemic is one example of how future dynamics can easily diverge from those described in scenarios that exclude such disruptive events.

To address this gap, we describe the methods and results from a workshop aimed at creating compelling, narrative-driven storylines of possible climate futures that met three criteria, being

\footnotetext{
${ }^{1}$ Stockholm Resilience Centre, Stockholm University, Stockholm, Sweden, ${ }^{2}$ Global Change Institute, University of the Witwatersrand, South Africa, ${ }^{3}$ Centre for Sustainability Transitions, Stellenbosch, South Africa, ${ }^{4}$ Copernicus Institute of Sustainable Development, Utrecht University, The Netherlands, ${ }^{5}$ Forum for Climate Engineering Assessment, School of International Service, American University, Washington, D.C., USA, ${ }^{6}$ Department of Environmental Science, American University, Washington, D.C., USA, ${ }^{7}$ Department of Plant Biology, University of Vermont, Burlington, Vermont, USA, ${ }^{8}$ Department of Computer Science, University of Vermont, Burlington, Vermont, USA, ${ }^{9}$ Independent science fiction author, South Africa, ${ }_{10}^{10}$ Independent fiction author, South Africa, ${ }^{11}$ Department of Environment and Sustainability, University at Buffalo, Buffalo, New York, USA, ${ }^{12}$ Institute of the Environment and Sustainability, University of California, Los Angeles, Los Angeles, California, USA, ${ }^{13}$ Center for Global Health Science and Security, Georgetown University, Washington, D.C., USA, ${ }^{14}$ German Institute for International and Security Affairs (SWP), Berlin, Germany, ${ }^{15}$ Climate Interactive, Washington D.C., USA, ${ }^{16}$ GEOMAR - Helmholtz Centre for Ocean Research, Kiel, Germany, ${ }^{17}$ Department of Environmental Science and Policy, Rosenstiel School of Marine and Atmospheric Science, University of Miami, Miami, Florida, USA, ${ }^{18}$ Leonard and Jayne Abess Center for Ecosystem Science and Policy, University of Miami, Coral Gables, Florida, USA, ${ }^{19}$ School of Environment, Enterprise and Development, University of Waterloo, Waterloo, Ontario, Canada, ${ }^{20}$ Sibley School for Mechanical and Aerospace Engineering, Cornell University, Ithaca, New York, USA, ${ }^{21}$ African Climate and Development Initiative, University of Cape Town, Cape Town, South Africa, ${ }^{22}$ Centre for Statistics in Ecology, the Environment and Conservation, University of Cape Town, Cape Town, South Africa
} 
integrative, dynamic, and creative, as well as being able to generate hypotheses about human behavior and social-environmental feedbacks that could inform quantitative models of climate futures. The focus on integrative scenarios recognizes that no single disciplinary approach is sufficient to capture major uncertainties of climate futures. Thus, perspectives from natural and social sciences, and when possible, from other stakeholders like civil society, business, and policymakers, should be integrated into scenario processes (Pereira et al. 2021). The focus on dynamic scenarios, rather than linear pathways to the future as if "on train tracks," emphasizes that the set of possible climate futures includes dynamic, branching pathways in which societies make choices in response to a changing climate. Different choices lead to very different futures; highlighting the potential for surprise events that could change the chosen direction is an important addition compared to widely used existing scenarios that deliberately exclude considerations of how human mitigation and adaptation behaviors change in response to climate change (van Vuuren et al. 2011, O'Neill et al. 2016, Riahi et al. 2017). This plurality of potential pathways and abrupt changes are critical to understand when thinking through governance for different trajectories (Schipper et al. 2021). Finally, the desire for creative futures stems from the need to create stories of the future that engage the research community, policymakers, and diverse publics in imagining possible (especially good) climate futures to facilitate better understanding of the diversity of potential futures and the pathways to them. Our starting point is the understanding that speculative, science fiction-style stories about climate change can provide important additional insights, not for what they predict about the future of the world, but for how they unpack who we are in the world in ways that can often surprise us (Milkoreit 2016, Beukes et al. 2017, Nature 2018). Thus, we argue that creativity builds the capacity to navigate uncertain futures (Moore and Milkoreit 2020).

Our chief aim is to offer a step-by-step guide to the modified Manoa Mash-up method that we used to generate these scenarios. We offer a walkthrough of how we used the method at our workshop, and a reflection on the broader implications of this method for generating more dynamic scenarios for climate change research that could better inform responses to climate change. The point is not to dwell in too much detail on the scenarios that "we" produced, but rather to say that those who work to model and imagine climate futures would do well to deploy tools that enable thinking differently about the future. We describe the content of the storylines we developed to tease out implications for further scenarios-based explorations and for future work unpacking dynamic interactions between climate and social systems. For example, the storylines hypothesized dynamics that are useful for informing additional research, such as their incorporation into quantitative modeling by integrated assessment models (IAM).

The novelty of our research is two-fold. First, it applies the Manoa Mash-up method to a new space of climate futures that expressly include technological interventions like solar radiation modification (SRM) and carbon dioxide removal (CDR). To do this effectively, it also contributes by expanding on the method with the use of techniques like wild cards to simulate surprise events and introduces branching points to illustrate that multiple pathways are always available. The results are at once useful explorations of established lines of inquiry and also generate novel, researchable insights. We show that the modified Manoa Mash-up approach is well-suited to pulling insights from a diverse range of participants and enables the rapid generation of narrative storylines and researchable insights. For these reasons the method should be of interest to other groups working on climate change and a range of other complex socialenvironmental challenges.

\section{WHY DO WE NEED SCENARIOS LOOKING AT CARBON DIOXIDE REMOVAL (CDR) AND SOLAR RADIATION MODIFICATION (SRM)?}

The Paris Climate Agreement aims to keep global mean temperature rise "well below" $2{ }^{\circ} \mathrm{C}$ above pre-industrial levels while pursuing efforts to limit warming to $1.5^{\circ} \mathrm{C}$. These ambitious targets for action, combined with evidence that even the $1^{\circ} \mathrm{C}$ increase to date has been harmful for ecosystems (Hughes et al. 2018), economies (Diffenbaugh and Burke 2019), and human health (Costello et al. 2009), are forcing a re-evaluation of global climate policy. Existing mitigation actions and pledges are insufficient in themselves to meet the Paris goals (Roelfsema et al. 2020). As such, future climate policies may extend beyond efforts to cut greenhouse gas emissions and adapt to a changing climate: societies might supplement traditional mitigation approaches with large-scale efforts to actively remove and sequester carbon dioxide, known as CDR, or may someday consider technologies that reflect a small percentage of sunlight back into space before it can warm the planet, known as solar geoengineering or SRM.

Still, even as interest expands in how SRM and CDR might have an impact on people and on the environment, SRM and largescale CDR remain largely in the realm of computer model simulations. For instance, nearly all existing proposals to limit warming to $1.5^{\circ} \mathrm{C}$, as implemented in IAMs, include multiple decades of large-scale CDR through bioenergy crops or other biomass growth with carbon capture and storage (BECCS) starting around 2030 (Rogelj et al. 2018). However, because of strong trade-offs with food production and biodiversity protection, this is a poor proxy for global CDR deployment and has been rightly criticized for engendering a kind of "magical thinking" within policy communities that might now take BECCS as some kind of operational response for the climate challenge (Geden 2016, Rayner 2016). Furthermore, the Carbon Dioxide Removal Modeling Intercomparison Project (CDRMIP) and, for SRM, the Geoengineering Modeling Intercomparison Project (GeoMIP) and Geoengineering Large Ensemble (GLENS), include a suite of scenarios for computer simulations described solely in geophysical terms (Kravitz et al. 2011, Keller et al. 2018, Tilmes et al. 2018). These and other climate simulations that imagine perfect technological control over SRM and CDR were not initially designed to guide decision making, but their use for projecting climate impacts has given them an outsize role in how scientists, policymakers, and the media envisage climate futures (Trisos et al. 2018, Proctor et al. 2018, Irvine et al. 2019). This is a critical issue that needs to be addressed because whether proposed CDR and SRM approaches can even promote the achievement of climate targets likely depends as much on the social, political, and environmental contexts in which they are used, as it does on what they might do to the climate. Having underlying storylines that can help climate and integrated 
assessment models address these nuances is critically important for adapting these models or developing new models to be able to better serve society (Shepherd et al. 2018, Saltelli et al. 2020).

Understanding the possible uses and impacts of CDR and SRM, therefore, requires thinking not just about radiative forcing, or staying within the remaining carbon budget, but also about politics and people. However, despite growing research and policy interest in CDR and SRM options over the last decade, there are relatively few scenarios that integrate knowledge from both social and natural sciences, as well as practical insights from decision makers, such as representatives from multilateral organizations. Furthermore, the dynamic, branching, qualitative scenarios developed through this method offer a novel way to explore some of the controversies surrounding these options and their inclusion in models (see Beck and Mahony 2017, Sugiyama et al. 2017). More linear scenarios can easily obscure the downside risks of incorporating CDR or SRM into hypothetical climate-policy portfolios, such as the potential for one or both approaches to reduce abatement efforts and the implications of CDR or SRM failing to materialize or being terminated prematurely. By contrast, dynamic scenarios can easily incorporate the interaction between CDR, SRM, and emissions abatement as an object of study, and branching scenarios allow for exploration of both the upside and downside risks of considering these technologies as part of a climate policy portfolio. This makes the method described here especially apt for studying these controversial approaches.

\section{THE ADAPTED MANOA MASH-UP METHOD}

To generate integrative, dynamic, and creative scenarios for thinking about climate change and any potential role for SRM and CDR in the structuring of climate change responses, workshop facilitators implemented an adaptation of the Manoa Mash-Up method for scenario generation in a five-day, participatory workshop. Additional methodological details can be found in the Supplementary Material.

The Manoa Mash-up method was initially developed for the Seeds of Good Anthropocenes project (Pereira et al. 2018) and subsequently used by the Intergovernmental Science-Policy Platform on Biodiversity and Ecosystem Services (IPBES) scenarios and models expert group as part of their innovative approach for new desirable futures for nature (Pereira et al. 2020). In the Manoa Mash-Up method of scenario generation, participants begin from short descriptions of various "seeds" of future states of the world. Each seed is something that plays a relatively small role in the world today, but which could grow to play a major role in the far future. For instance, artificial intelligence is less widespread now, but it could grow to become as important in the future as the internet is in the present. Starting from these seeds and working in small groups, the participants:

1. Imagine each seed in a "mature condition" by briefly describing the role each seed might play in the distant future;

2. Build a Future Wheel for each seed that describes primary, secondary, and tertiary impacts of the seed across multiple sectors when the seed is in its imagined mature condition;

3. Connect and clash the Future Wheels by identifying mutually reinforcing or contradictory interactions between the elements of each Future Wheel;
4. Develop a bare-bones story of this emergent future that connects the various Future Wheels into a coherent narrative;

5. Develop pathways to this future by thinking about what would have to change to get from the present to that future and what would have to happen along the way for such changes to occur.

The Seeds project is underpinned by an appreciation that "the unknowable future cannot be grasped from the point of view of the search for probable futures" (Miller 2013:107) and that this requires new methods. It extends the Manoa method (Schultz 2015), which uses horizon scanning as a starting point to imagine far futures, by engaging the potentially transformative power of storytelling (Milkoreit 2016, Evans 2017). The Manoa Mash-Up method, as described here, lends itself to creating scenarios that satisfy two of the three criteria outlined above: given an interdisciplinary group, it naturally allows participants to integrate natural and social scientific knowledge, and it produces richly detailed narratives to engage stakeholders and communicate key aspects of possible futures.

To ensure more dynamic scenarios, we extended the Manoa Mash-Up method in two main ways. First, we allowed the narratives to branch at key decision points, highlighting how different responses to social or environmental events lead to very different futures. Second, at unpredictable intervals during the process, the facilitator (literally) threw "wild cards" at the groups, i.e., surprise social or environmental events that the participants could incorporate into their timelines or narratives. These two additions pushed participants to think about how future societies might react to events, rather than simply extrapolating from current trends.

\section{Participants}

The workshop took place at the National Socio-Environmental Synthesis Center (SESYNC) in Annapolis, Maryland in May 2019, as the first in a series of workshops aimed at the development of new scenarios and models to understand the roles that CDR and SRM might play as forms of response to climate change. The interdisciplinary participants who attended the whole workshop are listed as co-authors, including the three speculative fictions authors.

The workshop took place as part of a SESYNC Pursuit, which is a collaborative team-based synthesis research project focused around emerging social-environmental system topics in which groups are encouraged to synthesize data, develop and apply models, and couple quantitative and qualitative data/information in new ways. As such there were certain restrictions in terms of the number and types of participants that we could include. Rather than a participatory workshop with stakeholders, this was an expert-driven process with all participants coming from research and policy backgrounds, except for the three sciencefiction writers that were included to strengthen the creative aspect of the process. Science-fiction prototyping based on Merrie et al. (2018) was a key addition to the original Seeds workshop process that built on the inclusion of artists to foster creativity (RaudseppHearne et al. 2019).

As per SESYNC protocol, there is a code of conduct that ensures all viewpoints shared at the meeting can be included in subsequent publications, and all participants are invited to contribute as co- 
Fig. 1. An outline of the workshop process.
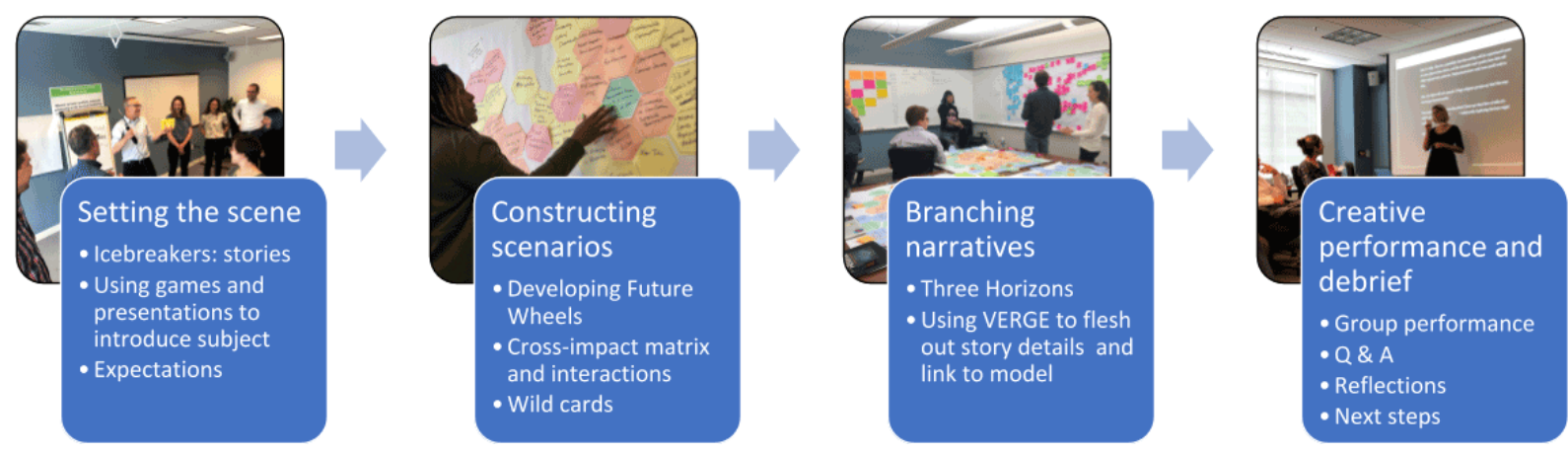

authors. As Pursuit endeavors normally extend across a series of three or four linked workshops and interstitial activities, it was important to ensure that there was sufficient overlap in skills with those experts who were to attend subsequent meetings that focussed more on modeling. There is also a requirement for "new networks" to be formed and so there is another limitation in who can be asked to participate because they should ideally not have previously collaborated with the workshop hosts. As such, the final group of participants was decided based on all of the above factors and their availability to attend a five-day workshop in May 2019. The 19 workshop participants were drawn from a crosscutting group of experts in climate science, social science, and policy with various backgrounds and expertise (Table 1).

Table 1. Workshop participant information.

\begin{tabular}{ll}
\hline \hline Description & Category \\
\hline Range of research domains & Engineering \\
& Complex systems \\
Ecology & Atmospheric physics \\
& Biogeochemistry \\
Health & Philosophy \\
Geography \\
Economics \\
Assessment science \\
Sustainability science \\
Literature/creative writing \\
Climate \\
Public policy \\
International relations \\
Atmospheric science \\
11 self-identified as male \\
7 self-identified as female \\
1 preferred not to say \\
USA 11 \\
South Africa 4 \\
Germany 2 \\
Geographic region & Canada 1 \\
& Italy 1 \\
\hline
\end{tabular}

The organizers pre-assigned participants to smaller groups based on their complementary expertise, both in terms of disciplinary background and in terms of experience with SRM and CDR as subject matters. Although this led to some groups being more biased in terms of gender (one group only had one woman; Table 1), ensuring a broad range of expertise within groups enabled each group to integrate knowledge from various disciplines. Although it is impossible to create a perfectly complementary group because the main aim was to get as broad a spread of diverse visions of the future as possible, these pre-allocated groups (each with one science-fiction writer) were constituted based on ensuring as wide a range of views on SRM and CDR as possible and it was hoped that groupthink could be avoided as each individual was an expert in their field and would be able to justify the basis for their reasoning based on their own expertise. However, it must be acknowledged that the resulting storylines were influenced by the participants and their grouping and that very different storylines could have emerged with different people in the room. At the same time, by following the same methodological approach that aims to maximize diversity based on expert knowledge, it is expected that even with a different set of participants and starting seeds, the range of futures covered by the scenarios would be similar to those that emerged during this exercise even if the stories themselves were very different.

\section{The workshop process}

The workshop's success hinged on participants' willingness to engage with one another and with the subject matter in unorthodox ways. To set the right tone for the workshop, the first half-day alternated between "intellectual scene-setting" through more academic presentations of background material on shared socioeconomic pathways and representative concentration pathways, a presentation on storytelling from the science-fiction writers, and playing a modified version of Decisions for the Decade, a game about responding to climate risks that involved geoengineering in the form of using an electric knife to cut a dice made from sponge to alter the probability of a climate hazard (Jones 2018; see https://vimeo.com/215056621). These exercises aimed to contextualize the workshop and break down disciplinary cliques and personal barriers between participants (see Appendix 1 for more details). The participants were then allocated into their three smaller groups in which they spent most of the rest of the workshop. The overall structure of the workshop is captured in Figure 1.

\section{Imagining seeds in mature condition}

The initial three seeds that are used as starting points for the visioning process in each group are central to the kinds of stories that emerge. As the storylines in each group emerge, new dynamics come into play that are not necessarily based on the starting seeds, but the seeds nevertheless contribute significantly to how the final 
narratives emerge. Because we wanted to be as participatory as possible, in the month prior to the workshop, the core organizing team invited participants to suggest potential seeds for the process. They were asked to suggest interesting socialenvironmental or economic-political seeds that were underway in the present that could play out in interesting ways in the future, especially when they clashed with SRM and/or CDR technologies. Because an aim of the workshop was to increase creativity and diversity in futures (that is a core specialty of the Manoa method), subject to the constraint that each group would need at least one category of SRM or CDR as a seed, the organizing team chose seeds from the list generated by participants and allocated them across the three groups to ensure that each group had three seeds that would interact in diversely interesting ways (Table 2). For ease of reference, each group will be referred to as the SRM group, the CDR group, and the SRM and CDR group that used a combination of both interventions (see Fig. 2).

Fig. 2. A figure depicting John Shepherd's "napkin diagram" that hypothesizes how solar radiation modification (SRM), carbon dioxide removal (CDR), and mitigation efforts could impact global mean temperature over time, relative to the business as usual (BAU) trajectory (Long and Shepherd 2014 MacMartin and Kravitz 2019, Reynolds 2019).

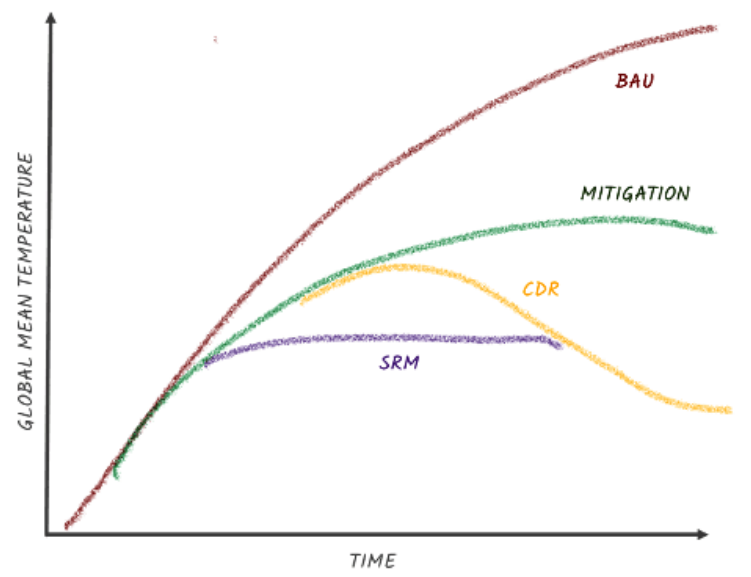

The choice of seeds definitely influenced the final narratives, but more in a way that forced the teams to engage with different social, political, and economic realities based on the kinds of perspectives to which each of the seeds alludes. Again, as with the range of participants, although the seeds do have a large effect on the final visions, the breadth of the dynamics that unfolds is the important component. There are a myriad possible storylines that the scenario process could develop, given the multiple dimensions of the process, but the important aspect is to ensure that the design meets the ultimate aim of the workshop. In this case, that was to generate creative and dynamic narratives of climate futures incorporating the use of SRM and/or CDR, while accounting for important interplays between biophysical and social dynamics (that is, being integrative). It is also important to note that, had different seeds been paired with the SRM and CDR response options, potentially very different storylines could have emerged. Because this was the first time this group was undertaking such a scenario process for this topic and there were time constraints, only one configuration of the seeds was possible. However, subsequent work could look at combining the seeds in different configurations to derive a wider set of final narratives that would make comparison more robust. For more critical discussion on how the seeds shape the final narratives in this method, see Pereira et al. 2018, Raudsepp-Hearne et al. 2019, and Rana et al. 2020.

After the introductory sessions, the organizers gave each group short descriptions of their assigned seeds, along with the instruction to describe each seed in its mature condition. The "mature condition" refers to what the group thinks the seed would look like if it were no longer marginal, but the dominant way of doing things (Pereira et al. 2018). Table 2 shows the seeds that each group received and the phrase or statistics that each group chose to characterize the seed's mature condition. Note that in describing their seeds in their mature condition, neither the SRM nor CDR groups felt it necessary to specify the mature condition of their respective climate change response option as a particular technology, rather saying only that SRM and CDR technologies or approaches had been widely deployed.

\section{Building Future Wheels and mapping interactions}

Once the groups had settled on an imagined mature condition for their seeds, they explored the implications of those mature conditions using a graphical method known as a Future Wheel. The Future Wheels, depicted in Figure 3, helped participants collectively brainstorm the direct impacts of their mature seeds on the world, followed by secondary and tertiary effects of those primary impacts. To think through the various potential impacts in a structured manner, participants were prompted to consider social, technological, economic, environmental, political, and value impacts, based on the STEEP-V framework (Schultz 2015). For example, the SRM group envisioned massive unemployment as a primary impact of mature artificial intelligence, the secondary impacts of which included universal basic income and "more room for human expression," but also social unrest.

Sometimes groups identified mutually incompatible possible impacts from a single seed. In those cases, they often added two contradictory implications to the Future Wheel with the intention of choosing one of them later in the process. For instance, the CDR group imagined that large-scale afforestation and reforestation could manifest as either regenerated wild forests or as highly managed plantations. Both possibilities appear in that group's Future Wheel as secondary implications of CDR, though only one ended up appearing in the group's final narrative.

Once the groups had completed the Future Wheel for each seed, they discussed and mapped out the connections between different impacts of the three seeds, including interactions between different implications of the same seed and interactions between implications of different seeds. The groups were instructed to identify the impacts of the seeds in their mature conditions that they found particularly interesting, and to note specific examples. For instance, participants identified interesting interactions between mature, climate-adapted belt and road infrastructure coupled with a strong voice for global South countries that emerged during their discussions of SRM deployment. It was also important to identify contradictions, surprising possibilities, and counterintuitive outcomes, such as the replacement of nation 
Table 2. The nine seeds allocated across the three groups. The description is the exact text that each group received about their seeds. The mature condition is the statement that they used as the central starting point for each Future Wheel.

\begin{tabular}{ll}
\hline \hline Seed & Description \\
\hline $\begin{array}{l}\text { Solar Radiation Management (SRM) Group } \\
\text { Seed: Solar Radiation }\end{array}$ & $\begin{array}{l}\text { Solar radiation management (SRM), also known as solar geoengineering, involves cooling the planet by reflecting a small fraction of } \\
\text { Management }\end{array}$ \\
& incoming sunlight back into space before it can warm the Earth. Prominent proposals for implementing SRM involve stratospheric aerosol \\
& would involve spraying particles into the lower atmosphere over the oceans to brighten low-lying clouds. Other proposals include making \\
& the Earth's surface more reflective, i.e., for instance, by installing white roofs, genetically modifying crops, or producing microbubbles in \\
& \\
& lakes, ponds, or oceans. \\
& Solar radiation management is sometimes described as "fast, cheap, and imperfect." It would be fast in that it could reduce global average \\
& temperature within a few years, but that cooling would last only as long as deployment continued. It would be relatively cheap (compared to \\
& mitigation) in that the direct costs of implementing SRM would likely be much less than decarbonizing the global economy (some estimates \\
& suggest direct costs on the order of a few billion dollars per year), but uncertain indirect costs could add considerably to the direct costs. It \\
& would be imperfect in that it could not precisely restore preindustrial climate and would instead create a new climate with different \\
environmental risks, but some climate models suggest that SRM could reduce overall climate risk compared to a world with substantial \\
climate change. This combination creates tension over SRM testing and deployment.
\end{tabular}

Mature condition of seed: SRM [is] deployed

Artificial intelligence is not a singular technology but rather a broad and diffuse class of technologies. Artificial intelligence encompasses everything from smart assistants like Siri and Alexa to the algorithms that sit behind many modern financial decisions to the "brain" for self-driving cars and autonomous weapons systems. Artificial intelligence is also an accelerator of other kinds of change. It can be thought of as a kind of techno-steroid, i.e., it is inside and a driver of an increasing number of other technologies and processes, and this reach of $\mathrm{AI}$ is accelerating and growing more pervasive.

Even in its current nascent condition, AI is a large and expanding component of the global economy. Artificial intelligence in a more mature condition could bring great benefit to humankind and to the planet. The growth of AI also, though, poses significant and serious risks.

Mature condition of seed: Artificial intelligence is pervasive as predictive software and autonomous machines The Belt \& Road Initiative (BRI) is the name given to a massive Chinese-led infrastructure and development project. The basic idea is to link China via land and sea to countries in Central and South Asia and on to Europe ("the Silk Road Economic Belt") and via a different route to the nations of SouthEast Asia, the Gulf countries, North Africa, and on to Europe ("the New Maritime Silk Road"). The effort includes the building of new ports, energy infrastructure, and transportation and telecommunications networks, all coupled with investments in agriculture, mining, manufacturing, and a range of other sectors. The BRI was announced in 2013, with a targeted completion date of 2049. Cost estimates top US\$4 trillion.

Mature condition of seed: Chinese-built infrastructure [span] across whole of Global South and Europe

Carbon Dioxide Removal (CDR) Group

Seed: Carbon Dioxide Carbon dioxide removal technologies have the potential to remove large amounts of $\mathrm{CO}_{2}$ from the atmosphere and store it on land, Removal underground, and/or in the oceans. Technologies such as direct air capture can also be used to harvest $\mathrm{CO}$ for creation of products such as fuel for transport and bubbles for beverages. The cost of removing a ton of $\mathrm{CO}_{2}$ varies depending on the technology and energy required to operate it, as does the length of storage of the $\mathrm{CO}_{2}$.

Multiple organizations have been started based on the intention to sell carbon credits from carbon capture and/or sell $\mathrm{CO}$ or products made from $\mathrm{CO}_{2}$. These include direct air capture companies such as Climeworks in Switzerland and Carbon Engineering in Canada, ocean fertilization companies such as Oceanos (also in Canada), and re/afforestation projects.

Integrated assessment models have used large amounts of bioenergy with carbon capture and storage (BECCS) to meet mitigation requirements for achieving global average temperature targets.

Mature condition of seed: CDR technologies [are implemented]

Seed: Continued Rise of The consolidation of economic and social power within a smaller number of large multinational corporations has accelerated in the first Multinational The consolidation of economic and social power within a smaller number of large multinational corporations has accelerated in the first
decades of the 21 st century, including in the financial, food, and technology sectors. Companies such as Amazon, Ali Baba, and Google now integrate across technology (including fintech), retail, food, and health sectors.

Corporations

These large corporations contribute to or mitigate climate change by enabling economic activities that create greenhouse gas emissions and through various forms of land-use change. A company like Walmart, for instance, is acknowledged as a leader in the installation of solar panels on its stores and warehouses and in the tracing of greenhouse gas emissions through its supply chains. The company is also criticized, though, for speeding up global resource extraction and consumption and baking in cultures of consumerism.

Mature condition of seed: World's largest 20 companies control $80 \%$ of gross world product

Seed: Extinction Rebellion In late 2018, European activists began two independent social movements to promote climate action. In the UK, activists organized a and School Strikes peaceful "rebellion" against the British government over the government's perceived lack of ambition in addressing climate change. In Sweden, sixteen-year-old Greta Thunberg went on a "school strike for climate." Both Extinction Rebellion and Thunberg called on governments to treat climate change as a crisis.

These movements gathered steam quickly. In addition to various protests in late 2018, Extinction Rebellion conducted large-scale civil disobedience activities around London in April 2019, prompting the UK House of Commons to declare a "climate emergency." Groups modeled on Extinction Rebellion have arisen in developed and developing countries around the world. Thunberg's school strike has also spread to countries around the world, with hundreds of thousands of "school strikers" calling on their governments to enact aggressive mitigation measures.

Mature condition of seed: Social movement forces governments to achieve $\leq 0[\mathrm{GHG}]$ emissions 


\section{Solar Radiation Management and Carbon Dioxide Removal Group} Management and Carbon Dioxide Removal

[This group received the descriptions of SRM and CDR given above, and then the facilitator had a participant draw and explain a version of John Shepherd's "napkin diagram" (Long and Shepherd 2014, MacMartin and Kravitz 2019, Reynolds 2019), like the one in Figure 2, which depicts one possible use of mature SRM and CDR technologies: CDR complements emissions abatement to reduce global warming over the very long run, with SRM used as a temporary measure to limit peak warming.]

Seed: Universal Basic

Mature condition of seed: Deployment of portfolio of CDR options taking 5 GtCO2/yr into storage, AND SRM options capable of reducing mean [temperature] by $2^{\circ} \mathrm{C}$

Income

A universal basic income (UBI) is an unconditional periodic cash payment given to each individual in a jurisdiction, typically paid for out of the public purse. It is unconditional in the sense that it is paid automatically without regard to the individual's income, wealth, employment status, marital status, etc. Some proposals involve monthly payments large enough to satisfy all of an individual's basic needs, whereas other proposals envision higher or lower payments.

A number of jurisdictions have experimented with UBI programs. For instance, Finland began a small pilot program in 2017. Utrecht and Sao Paulo have pilot programs. The non-governmental organization GiveDirectly has been running a privately funded pilot program in Kenya since 2017. Alaska has a program similar to a UBI, the Alaska Permanent Fund, in which all residents of Alaska receive an annual check paid for out of tax revenues from oil and gas production.

Seed: The Wall

Mature condition of seed: $90 \%$ of citizens of half the countries in the world receive an automatic cash grant monthly Border walls are on the rise. Physical barriers have been erected between India and its neighbors Bangladesh and Pakistan; a concrete wall close to 20 feet ( 6 meters) in height and running for 400 miles ( 643 kilometers) separates Israel from the West Bank; a fence topped with barbed wire stretches for 325 miles (523 kilometers) along the Hungarian border with Serbia and Croatia; cries of "build that wall" echo at Trump rallies in the United States. Walls are meant to serve the practical purpose of limiting the flows of people and items between two places. They also serve a symbolic purpose domestically and internationally, shaping relations between neighboring states and the people who live in those states.

In contrast, recent examples also exist of countries accepting large numbers of migrants and forced migrants such as Germany taking in more than 1 million refugees in 2015 and 2016.

Mature condition of seed: Extreme fragmentation into walled communities (national + subnational)

states with cyber-states. Because some of the Future Wheels were unwieldy, instead of drawing on the figures, teams used wool yarn to highlight these connections (Fig. 4). They found this to be a useful adaptation that allowed for connections to be made more easily as well as allowing for changes as discussions about the emerging relationships continued.

To further deepen participants' understanding of the potential interactions between seeds, each group also completed a crossimpact matrix to identify ways in which one seed could impact another, and vice versa (Fig. 5). As a final step on the first day, which had involved several hours of in-depth dialogue, each group was asked to stand back, contemplate the rich material they had generated, and start looking for emerging narratives and storylines of a future vision for the development and deployment (or a turning away from) SRM and CDR. After getting a sense of the emerging story, each group had to come up with some news headlines representing their future vision and a statistic. The groups used these to present their "scenario skeletons" to each other at the end of the day.

\section{Developing pathways to imagined futures}

Because the process needed to emphasize surprise, dynamism, and potential key bifurcation points in how the future might unfold, a core focus of the process was to identify branching pathways into the future. To do this, the groups used the Three Horizons framework (Sharpe et al. 2016) to connect their future visions to the present. In this case, the Three Horizons framework was used as a graphical tool to encourage participants to imagine the world at different time horizons (Fig. 6), including the present (1st Horizon), the far future (3rd Horizon), and a transition zone between the two (2nd Horizon). Participants agreed to construe the "far future" as meaning the end of this century.

Facilitators encouraged each group to imagine the world at the 3rd Horizon as a positive vision of the world encoded in the
Future Wheels. Although this was not always easy, and some negative outcomes were inevitable, trying to dig deep into thinking that could see how a better outcome could arise forced the participants into a more creative mode. Then, they identified system components and paradigms in the present (1st Horizon) that would need to change or disappear for the world of the far future (3rd Horizon) to emerge. In thinking about the world at the 2nd Horizon, groups explored the clashes and synergies between the waning and emerging paradigms in the transition between the 1st Horizon (the present) and 3rd Horizons (end of the century). This is where the key bifurcation points were identified. In addition to charting the growth of the seeds, the Three Horizons framework helped groups identify other novel trends, ideas, and developments that would need to become dominant to achieve the futures that they had started to envision.

To produce dynamic, branching pathways, facilitators encouraged participants to identify critical points that opened up alternative pathways based on how different dynamics could play out. All three groups charted multiple pathways based on different outcomes at those "branching points," leading to a range of possibilities. For instance, the CDR group identified the point at which the world first commits to large-scale CDR as a branching point. They envisioned two distinct pathways forward from that point, depending on how societies respond to the prospect of large-scale CDR. In one pathway, societies recognize the limitations of CDR and combine it with rapid cuts in greenhouse gas emissions. In the other, societies treat CDR as a reason to avoid cutting emissions quickly, leading to much higher levels of warming. As this example illustrates, branching points often emerged when groups faced a point in their narrative where they could imagine the storyline going in radically different directions depending on the sign and strength of highly uncertain social feedbacks or climate-social dynamics. The branching pathways that the groups developed formed the core outcome of the process 
Fig. 3. Future Wheels built up from seeds in their mature conditions from the solar radiation modification (SRM) and carbon dioxide removal (CDR) groups, respectively. The left panel is a reconstruction of the Future Wheel generated by the SRM group on the Belt and Road Initiative seed. The right panel is an image of the CDR group's Future Wheels for each of their three seeds. The central hexagon in each wheel represents a seed. The next ring of hexagons (the orange hexagons) represents first-order implications of the seed, and additional colors represent second- and third-order implications.
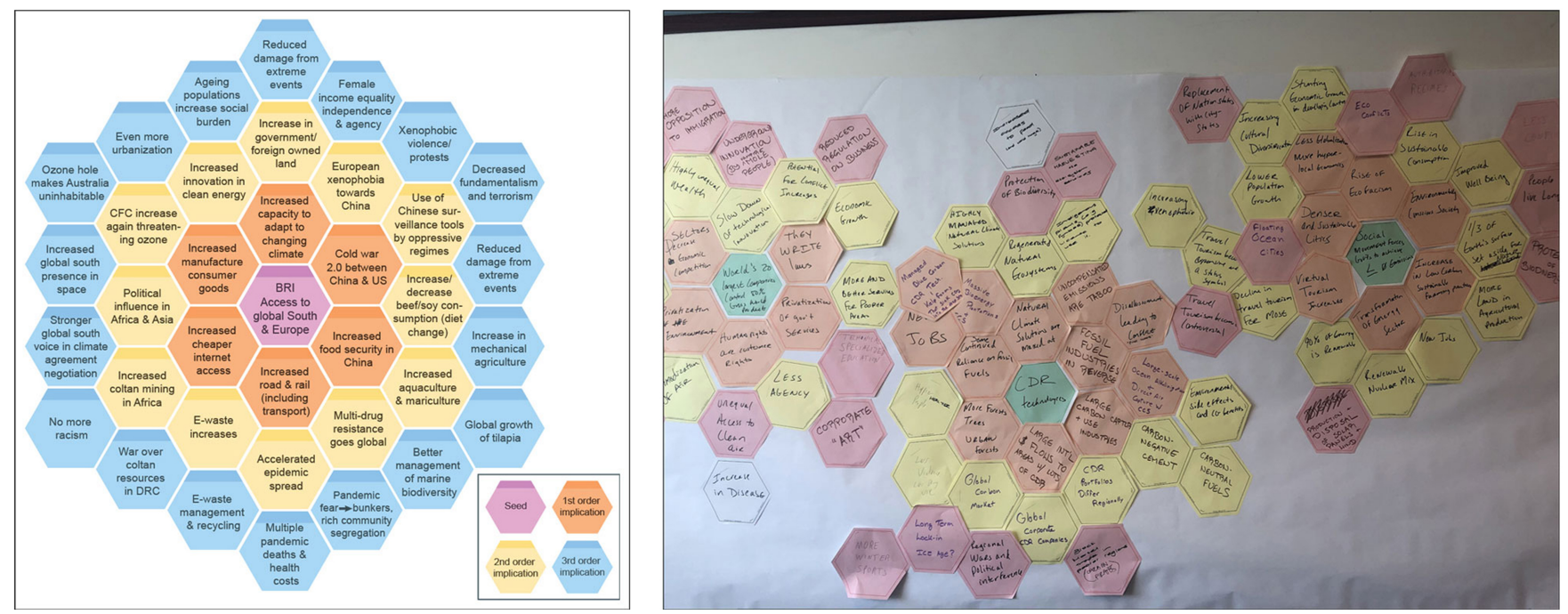

Fig. 4. The solar radiation modification (SRM) group's Future Wheels. The left panel is a reconstruction of the three Future Wheels built from the three initial seeds: SRM, artificial intelligence, and the belt and road initiative, and how subsequent first, second, and third order implications were mapped to generate the wheels. The left panel illustrates how the Future Wheels were clashed together using wool to connect implications between each wheel.
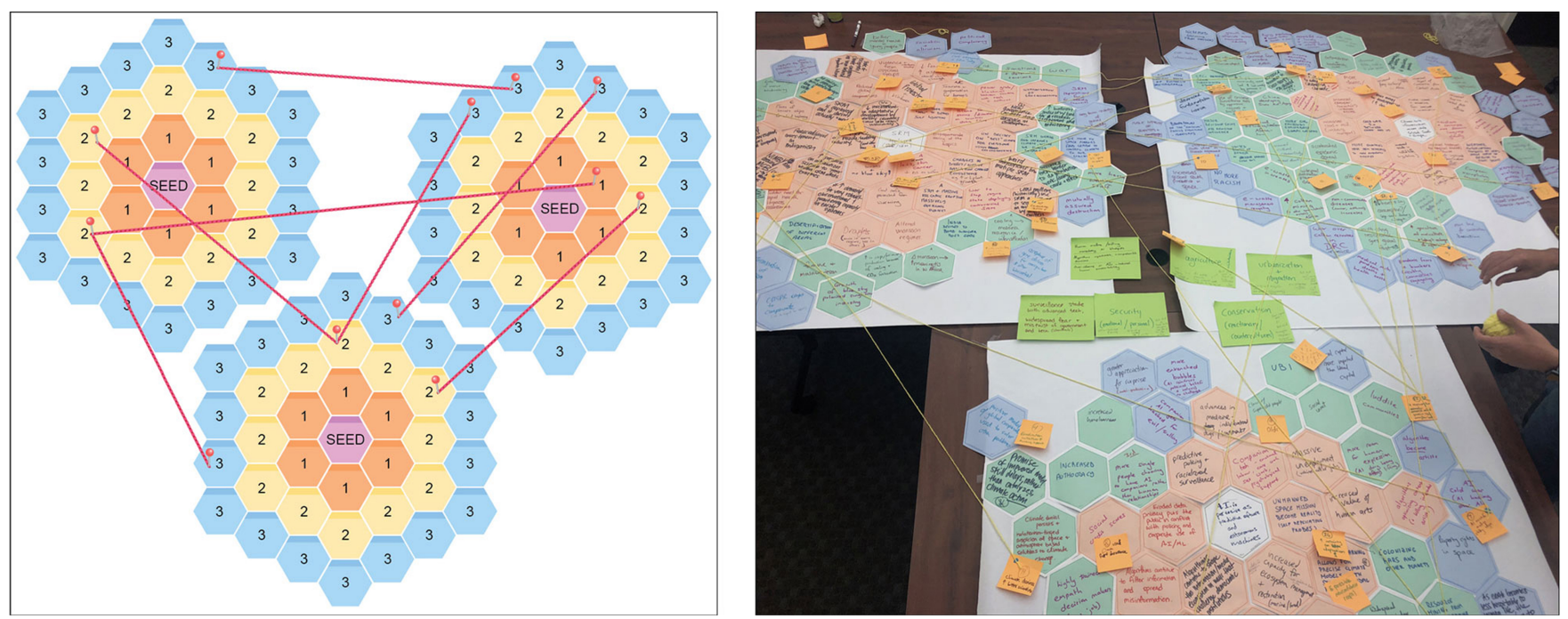
Fig. 5. Cross-impact matrix from the solar radiation modification (SRM) group describing the ways in which seeds could impact each other. Each group constructed a 3 x 3 matrix to consider how each mature seed would impact the other two mature seeds.
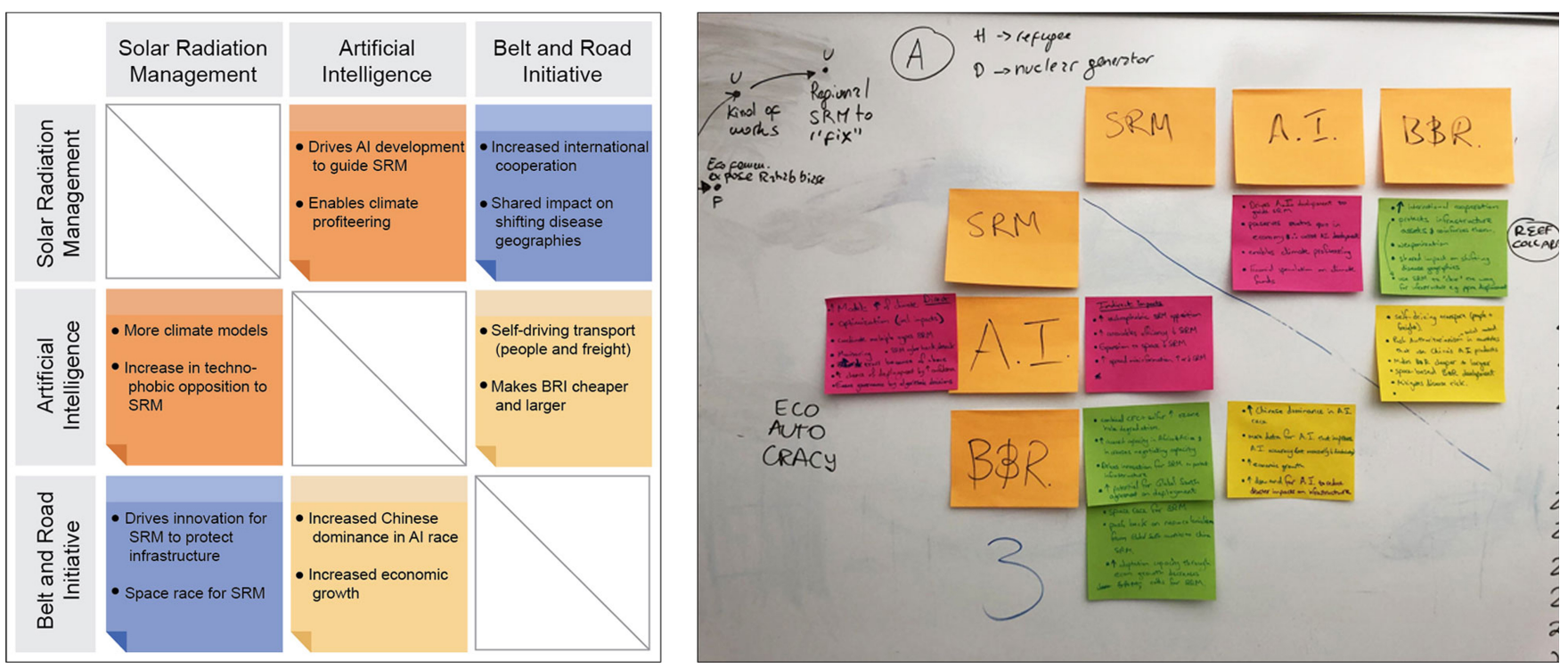

Fig. 6. The left panel illustrates a stylized version of the Three Horizons framework as implemented by all three groups with time on the horizontal axis and the state of maturity or dominance of seeds on the vertical axis. The 1st horizon is the present, the 2 nd Horizon is in the middle, and the 3rd Horizon is the far future on the right. The right panel shows the Three Horizons diagram for the carbon dioxide removal (CDR) group. Notes in the upper left describe the dominant conditions in the present, such as "fossil fuel vested interests." Notes in the upper right describe dominant conditions in the distant future, such as a "circular carbon economy." Notes in the lower left describe the state of the group's seeds in the present, such as "CDR innovation". Notes in the center describe changes that enable seeds to grow, such as "carbon utilization opportunities." Branching scenarios are visible in the CDR Three Horizons diagram with pink notes near the center top and center right describing alternate pathways deviating from the "main" scenario.
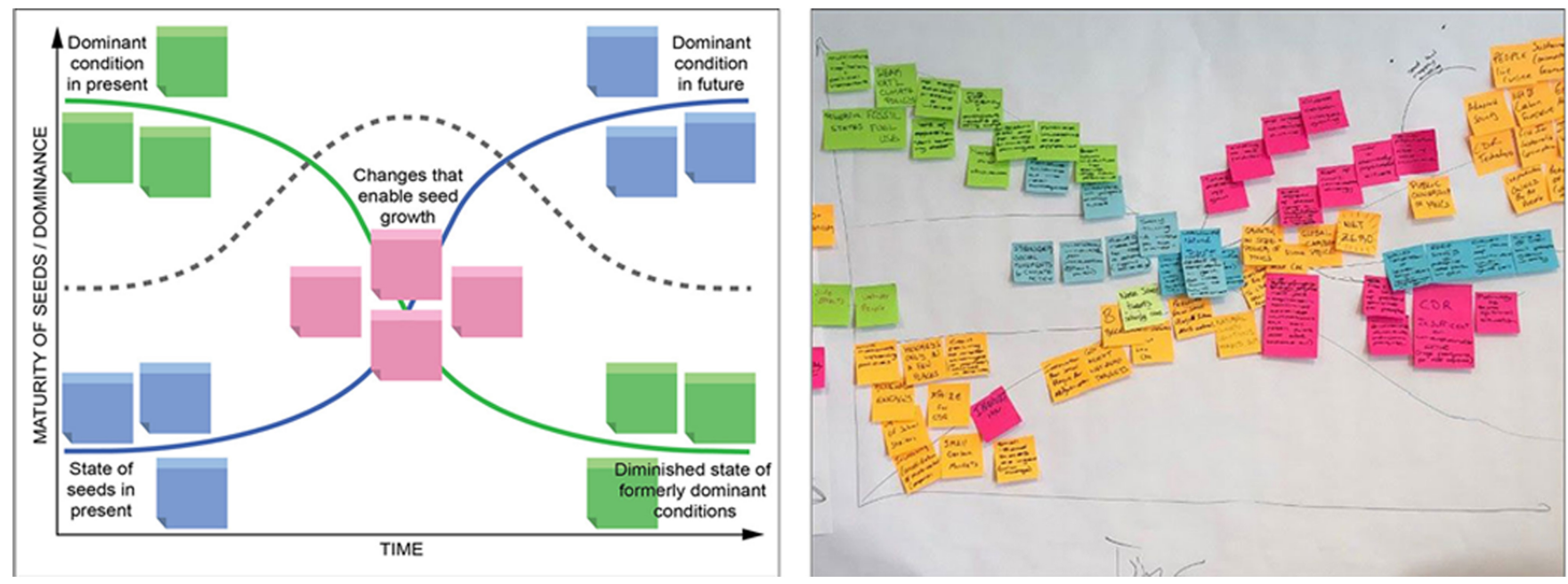
Table 3. Wild cards or surprises for the groups. The surprise column contains the text of the wild cards thrown at various groups. For each row, the playing card icons in columns 2-4 indicate which group received the wild card described in column 1. Note: SRM $=$ solar radiation modification; $\mathrm{CDR}=$ carbon dioxide removal; $\mathrm{Gt} \mathrm{C}=$ Gigatons of carbon.

\begin{tabular}{|c|c|c|c|}
\hline Surprise & SRM & CDR & $\begin{array}{l}\text { SRM \& } \\
\text { CDR }\end{array}$ \\
\hline $\begin{array}{l}\text { Permafrost collapse: sudden permafrost collapse with around } 2^{\circ} \mathrm{C} \text { of warming in the } 2060 \text { s accelerates release of } \\
20-80 \mathrm{Gt} \mathrm{C} \text { into the atmosphere. }\end{array}$ & $\S \S \S$ & & \\
\hline $\begin{array}{l}\text { Reef collapse: repeated marine heatwaves from a series of climate change supercharged El-Ninos during the } \\
\text { 2030s result in pan-tropical coral reef collapse, with a switch to algae dominated, shallow-water marine } \\
\text { ecosystems and a rapid shift away from equatorial regions for tropical fish species. Fish catches in the tropics } \\
\text { decline } 50-60 \% \text {, as does ecotourism, a major source of income for tropical and sub-tropical countries. }\end{array}$ & $\S \S \S$ & $\S \S \S$ & $\S \S \S$ \\
\hline $\begin{array}{l}\text { Ice sheet collapse: climate scientists establish that their projections of ice-sheet loss needed radical revision and } \\
\text { new results show a projected sea-level rise of } 5 \mathrm{~m} \text { by } 2100 \text { due to ice melt in West Antarctica and Greenland. }\end{array}$ & & & $\S \S \S$ \\
\hline $\begin{array}{l}\text { SRM technology: SRM tech has improved radically along with climate prediction models. Scientists and } \\
\text { engineers in } 2040 \text { are very confident that global aerosol injection could be used to rapidly reduce global warming } \\
\text { for } 10 \text { billion dollars per year. }\end{array}$ & & $\S \S \S$ & \\
\hline $\begin{array}{l}\text { Economic recession: a commodities and tech market bubble bursts in the } 2040 \text { s leading to a decade-long } \\
\text { recession, deeper than in } 2008 \text {. }\end{array}$ & & $\S \S \S$ & \\
\hline $\begin{array}{l}\text { Gender inequality: the last country in the world has banned abortion and this has brought about the future that } \\
\text { Margaret Atwood initially described in } A \text { Handmaid's Tale. }\end{array}$ & & & $\S \S \S$ \\
\hline
\end{tabular}

because it allowed for the groups to capture key dynamics, feedbacks, and tipping points that could be relevant to try and incorporate into models.

During the Three Horizons session, the facilitator introduced wild cards as "surprises" for the groups to take into consideration during their discussions. A wild card is "a future development or event with a relatively low probability of occurrence but a likely high impact on the conduct of business" (Steinmüller 2004:195). The rationale for this was to see how adaptable the stories were to real-world events in which surprises (or black swans) have important implications (Taleb 2007, Masys 2012). The wild cards also served as tools to force the participants' imaginations to derive plausible stories for how unlikely events might happen. The initial wild cards comprised a set of possible biophysical tipping points (Table 3), but facilitators later introduced more social surprises of future headlines to see whether groups could also incorporate these dynamics into the stories. These included references to speculative fiction like Margret Atwood's (1985) $A$ Handmaid's Tale that deals with issues of gender dynamics in society. To make this more fun, the wild cards were given to the group in the form of a plastic ball that one of the group members had to catch and read out to the others.

Although some wild cards had little or no effect on the emerging storylines, others proved pivotal. For instance, although all three groups received a wild card announcing the pan-tropical collapse of coral reefs, the CDR group made the event into a central point in their story because it sparked an inundation of climate refugees that the world needed to respond to. Whether the wild cards affected the storylines seemed to depend partly on group dynamics and partly on what else was happening in the narratives at the time when the wild card event occurred. In some cases, the wild cards forced the groups to really unpack what they considered "possible". For instance, the SRM and CDR group received a wild card in which sea levels rose five meters by 2100 . The group reacted skeptically, objecting that the described event was impossible. When facilitators pressed them to consider what it would take for the event to happen, the group delved into an extensive discussion of ice-sheet dynamics and devised a storyline in which a climate doomsday cult managed to plant a nuclear bomb under the West Antarctic ice sheet to accelerate sea-level rise. Ultimately, the group elected not to pursue that storyline further, excluding this wild card from their main narrative pathways. It did, however, force them to re-examine some important assumptions about what is possible versus what they thought plausible.

\section{Developing narratives}

After charting out the pathways from the present to various imagined futures, each group set about putting some flesh on the bones of their narratives to ensure that as much rich detail could be captured and compared across the groups. Using the VERGE or ethnographic futures framework (Lum 2014), each group was asked to fill in a table with some key questions exploring changes in the world (see Tables A2 and A3 in Appendix 1). VERGE prompts participants to consider different domains of human experience: in this figure, how do we define things, relate to one another, connect to each other (and the environment), create, consume, or destroy? In addition to these six VERGE categories, the organizing team had also included some specific questions related to climate and energy. The SRM and CDR group also got excited about trying to plot out a "Choose-your-own adventure" story to capture the discussions they had in developing their Three Horizons diagram and in particular the branching. The group used free software called Twine (https://twinery.org/) to prepare a draft of their narrative and the result was effective in explicitly showing key points of diversion in the narrative.

\section{Performance}

Allowing for the creative communication of these scenario narratives is a key component of the method (also known as embodied foresight; Floyd 2012). As a final step in the process, each group performed their stories in ways that showcased not only their visions of the future, but also how different choices at critical moments led to different futures. Each of the three groups presented their visions very differently. The SRM \& CDR group used the "choose-your-own adventure" story they had built in 
Twine to lead an interactive game in which the audience was able to make decisions that led to different futures. The SRM group started with a story technique inspired by one of the workshop ice-breakers ("fortunately and unfortunately" technique: see Appendix 1 for more information) and then went on to present a series of vignettes illustrating how different choices had led to three very different futures (Fig. 7), one of which did not even end up deploying the SRM technology. The CDR group started with a musical number (adapted from Wicked) describing the desirable future to which their narrative led, but which alluded to the turning points in the narrative at which point more problematic outcomes could have arisen (Fig. 8). See Appendix 1, Table A5 for more details about these performances.

Fig. 7. A diagram of branching pathways from the solar radiation management (SRM) group. Each colored curve represents a different storyline, with the "branching points" marked with a red dot where the storyline bifurcates. For instance, the green eco-autocracy line initially rises above the blue stumble $\&$ scramble line because one of the seeds (artificial intelligence, AI) plays a more important role in the ecoautocracy storyline at that point in time than it does in stumble $\&$ scramble, but stumble \& scramble later rises above ecoautocracy because AI reaches maturity in both scenarios while SRM remains immature in the Eco-Autocracy storyline. The gray social-unrest branch is truncated because the SRM group chose not to develop that storyline any further.

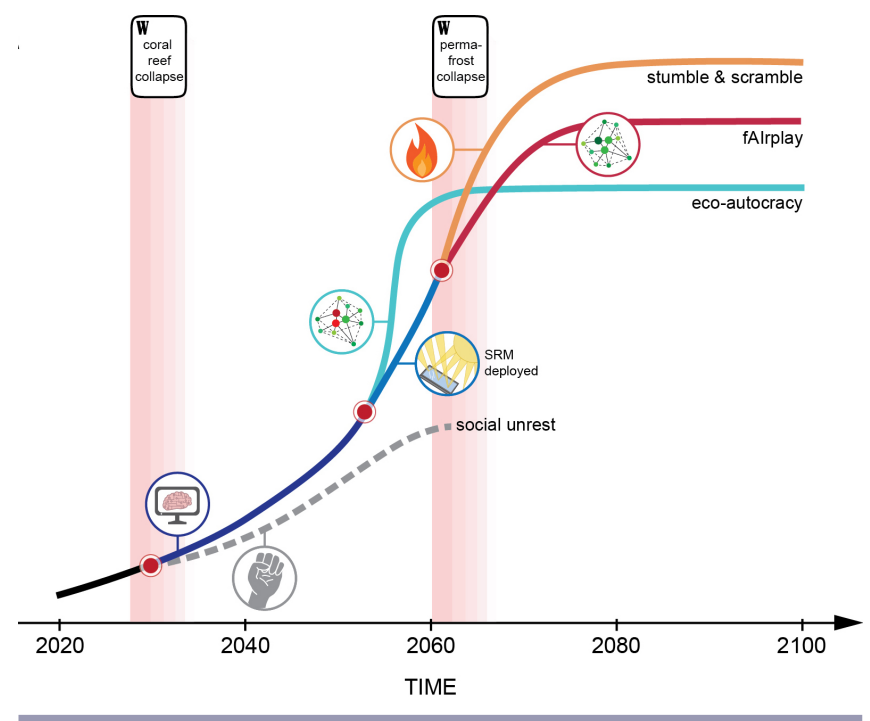

Analysis

Soon after the workshop concluded, representatives from each group met to analyze and synthesize the workshops' outputs. Using notes and physical outputs from the workshop, such as the Future Wheels and Three Horizons diagrams, each representative wrote narrative descriptions of the storylines their group developed, including the major branches. Each representative also described the key social-environmental dynamics identified by each group as driving the narratives of that group, as well as the causes of the branching in the narrative, and the connections between those dynamics and the branching. The representatives then compared the narratives, key social-ecological dynamics, the causes of branching, and the VERGE tables completed during the workshop across the three groups to identify important similarities and differences between the branching scenarios across the groups. As part of this synthesis, representatives were asked to abstract away from the specifics of the seeds, other than SRM and CDR, to consider how the broader social and environmental conditions explored affected the storylines and identify whether certain social-ecological dynamics were common in driving branching storylines across multiple groups of scenarios.

Fig. 8. A diagram of branching pathways from the carbon dioxide removal (CDR) group. Each colored curve represents a different storyline, with the "branching points" marked with a red dot where the storyline bifurcates. Although the first bifurcation results in the climate wars storyline, this eventually lands up in the same place at the ecohumanist revolution storyline although it goes through a much more turbulent path to get there. The second branching point leads to the suboptimal situation storyline in which fossil fuel interests continue to undermine action against climate change.

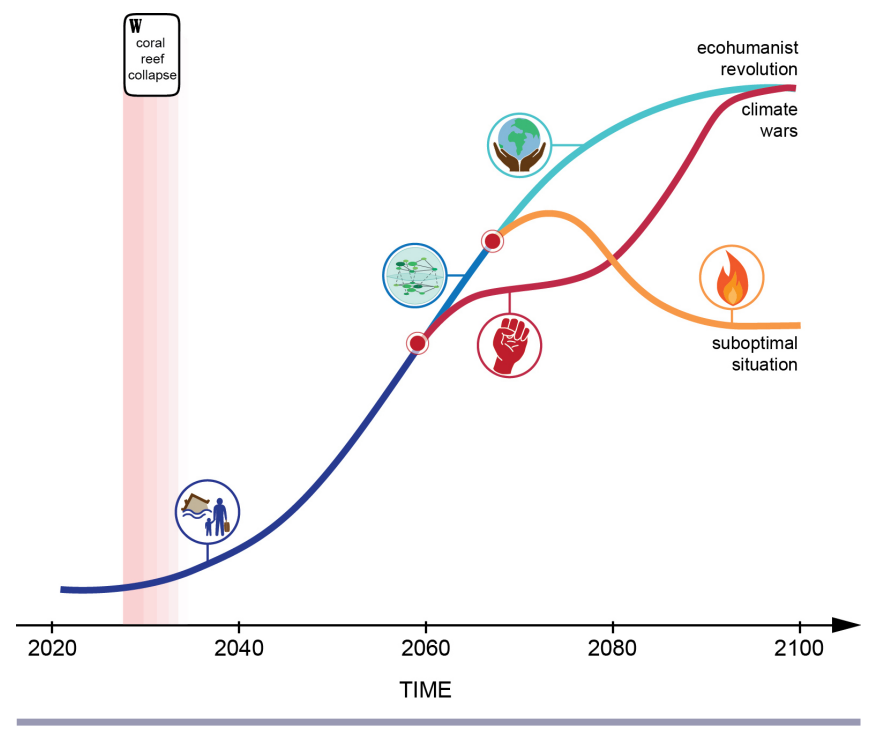

Methodological limitations and caveats

Although, when discussing SRM and CDR futures, there is the possibility of falling into particular tropes, such as that SRM will deter mitigation, it was felt that the seeds approach forced the participants to loosen a grip on these tropes, and rather than imposing them from the outset, to test how they might emerge, or not, within the storylines of interacting social, environmental, and political dynamics. For example, one of our storylines (fAIrplay, see Fig. 7) describes how SRM could increase motivation to mitigate greenhouse gas emissions and reduce inequality. That being said, although a futures method can help to avoid certain pitfalls, it is never fail-proof and the contingencies of group dynamics will always affect the outcome of any group process (Hebinck et al. 2018). It must therefore be acknowledged that the final scenarios are indeed constrained by the chosen method, which, although it was able to meet the workshop goals, did result in a particular set of narratives being constructed and these are very much determined by decisions made up front in 
terms of starting seeds, participants, their imaginations, and their group dynamics. The addition of other methodological innovations, such as wild cards and branching points, were also included to open up certain dynamics in the storyline (such as potentially unforeseen future events or key decisions leading to a bifurcation event). However, these, by nature, also directly affect the final narratives.

Drawing on the futures cone (Voros 2017), which emphasizes that the future does not only consist of projected, probable, or plausible outcomes, which tend to be captured in conventional environmental models, we were guided by the need to explore possible, preferable, or even preposterous futures to develop anticipatory capacities. By design, the method aimed to capture as diverse a set of narratives as possible, i.e., edging more toward the possible, preferable, and maybe even the preposterous, and so although the final narratives represent a particular slice of potential futures, the slice is hardly a narrow one. Rather, the final narratives do considerably open up the space of possible futures from existing scenarios exploring CDR and SRM in global climate models or integrated assessment models, such as the suite of GeoMIP, GLENS, and CDRMIP scenarios developed for computer simulations and described solely in geophysical terms (Kravitz et al. 2011, Keller et al. 2018, Tilmes et al. 2018). In particular, the scenarios explore a wide range of environmental, social/political, and technological aspects of climate futures based on the diverse set of seeds and wild cards that were selected to represent a mix of these domains. This allowed more holistic storylines to emerge, rather than focusing on just one of these dimensions as previous quantitative modeling has done (Kravitz et al. 2011, Ricke et al. 2013, Keller et al. 2018) or focussing narratives only on dimensions determining challenges to climate mitigation and adaptation, as with the SSPs (O'Neill et al. 2017), without also considering how climate impacts may feedback to change social systems. However, the storylines are not intended to be all-encompassing in any particular dimension. Rather, the results are intended to open up the conversation on the diversity of potential climate futures and especially branching points within these futures that could emerge from the use (or not) of SRM or CDR approaches, in conjunction with other changing social dynamics and choices made in response to climate impacts. There are important learnings and reflections that come from using this innovative method, including important implications for how to go about undertaking quantitative modeling and other awareness-raising and decision-making processes.

\section{RESULTS}

Each group produced a family of branching scenarios. Despite the rich variety of storylines and endpoints in these scenarios, some key similarities emerged in terms of the key feedbacks, variable, and dynamics that drive the stories. Note that groups were not asked to quantify key outcomes during this workshop, although the Climate Interactive En-ROADS climate simulator (https://www.climateinteractive.org/tools/en-roads/) was used to generate some very rough assumptions of warming under different choices in the SRM \& CDR group. Further, although each of the groups received a variety of wild cards, only some of these are incorporated into the final scenarios. Important variables, such as cumulative emissions and the amount of global warming, were described only qualitatively at this point, with quantification postponed until future workshops.

\section{Preliminary descriptions of scenarios}

\section{Solar radiation modification ( $S R M)$ group}

The SRM group, whose seeds were artificial intelligence (AI), the belt \& road initiative, and SRM, began from a near future in which AI drives job losses during the 2020s in the context of continuing trade wars between China and the United States. The SRM group briefly explored a scenario, which deviates from the main storyline at the first branching point (see Fig. 6). In this "social unrest scenario," countries fail to cope with AI-induced job losses and international cooperation continues to erode. The group did not develop this scenario in detail, but their consideration of it illuminates the non-trivial assumption in their other scenarios that humanity learns to manage the social effects of AI.

In the group's main scenarios, the job losses and the collapse of tropical coral reefs in the 2030s drive governments, especially in the global South, to provide new social and environmental protections, such as a universal basic income, climate adaptation measures, and the regional testing and moderate regional deployment of SRM, such as marine cloud brightening over reef ecosystems or the use of geotextiles in the Arctic. The storyline continues to a bifurcation point in the 2050s (branching point 2), depending on the success of mitigation (see Fig. 7). In the "ecoautocracy scenario," greenhouse gas emissions fall sharply for several reasons. Rising investment through the belt \& road initiative drives increases in renewables, nuclear energy, and CDR throughout the global South. Artificial intelligence-driven "social credit scores" incentivize climate-friendly choices by individual consumers, first in China and then beyond. Carbon prices rise around the globe, enforced by space-based monitoring of greenhouse gas emissions. Solar radiation modification technologies are developed but never deployed at a global scale due to the success of mitigation and adaptation.

In the other scenarios, greenhouse gas emissions rise after the second branching point because the belt \& road initiative drives economic growth, but efforts to reduce the carbon intensity of the economy falter. When the permafrost collapses in the 2060s (a wild card that was introduced for this group), the UN votes to deploy SRM globally through AI-guided stratospheric aerosol injection. The scenario bifurcates again at the third branching point, depending on the strength of the moral hazard effect from SRM (see Fig. 7). Moral hazard in this context describes people perceiving the problem of climate change to be solved by a technological fix and that this then undermines other efforts to mitigate or adapt to climate change (Lin 2013, Morrow 2014, Jebari et al. 2021). In the "stumble \& scramble scenario," a strong moral hazard effect reduces mitigation efforts substantially while SRM is deployed. Twenty years after SRM deployment begins, terrorist attacks on the SRM drones cause the abandonment of global deployment and a rebound of global warming. Various countries scramble to deploy SRM regionally, leading to serious geopolitical strife. In contrast, in the "fAIrplay scenario," a weak moral hazard effect means that SRM works in tandem with mitigation and adaptation to significantly reduce climate risk. New governance structures emerge to promote the equitable distribution of the benefits of AI.

\section{Carbon dioxide reduction (CDR) group}

The CDR group, whose seeds were CDR, multinational corporations, and extinction rebellion, began with a near future 
Table 4. Synthesis of the three scenario groups, focusing on the feedbacks and dynamics that drive branching and lead to different outcomes.

\begin{tabular}{|c|c|c|c|}
\hline Group & Scenario name & Key feedbacks and dynamics & What drives the branching? \\
\hline \multirow[t]{3}{*}{ Solar radiation modification (SRM) } & Eco-autocracy & $\begin{array}{l}\text { Effective mitigation eliminates } \\
\text { motivation for SRM }\end{array}$ & $\begin{array}{l}\text { Branching driven by social dynamics: } \\
\text { strength of mitigation (moderated by } \\
\text { coercive measures) and strong or } \\
\text { weak "moral hazard" effect. }\end{array}$ \\
\hline & Stumble \& scramble & $\begin{array}{l}\text { Strong "moral hazard" undermines } \\
\text { mitigation }\end{array}$ & \\
\hline & fAIrplay & Social response to inequitable SRM & \\
\hline \multirow[t]{3}{*}{ Carbon dioxide reduction (CDR) } & Ecohumanist revolution & $\begin{array}{l}\text { Constructive social response to } \\
\text { climate shock }\end{array}$ & $\begin{array}{l}\text { Branching driven by social response } \\
\text { to climate shock and by social } \\
\text { dynamics of mitigation and strength } \\
\text { of "moral hazard" effect. }\end{array}$ \\
\hline & Climate wars & $\begin{array}{l}\text { Destructive social response to climate } \\
\text { shock }\end{array}$ & \\
\hline & Suboptimal situation & $\begin{array}{l}\text { Strong "moral hazard" undermines } \\
\text { emissions reductions }\end{array}$ & \\
\hline \multirow[t]{2}{*}{ SRM \& CDR } & Coordinated city-states & $\begin{array}{l}\text { Degree of global coordination in } \\
\text { trade, mitigation, SRM, conflict } \\
\text { resolution }\end{array}$ & $\begin{array}{l}\text { Branching driven by social response } \\
\text { to breakdown of prevailing global } \\
\text { order. }\end{array}$ \\
\hline & Climate chaos & & \\
\hline
\end{tabular}

in which climate policy remains relatively weak, despite growing social pressure for mitigation. Beginning in the 2030s, a prolonged global recession accelerates the consolidation of economic power as a small number of large multinational corporations outcompete their struggling rivals. In about 2040, the collapse of coral reefs sparks massive migration out of the tropics.

The storyline first bifurcates (Fig. 8) here, depending on how societies cope with massive migration. In the "climate wars scenario," the recession- and climate-driven migrations prompt a series of civil and international conflicts that devastate the global economy. In the other storylines, powerful multinational corporations use the social upheaval as an opportunity to seize power from states, and increasingly powerful environmental movements use the upheaval as an opportunity to foster a global "ecohumanist" ethos that prioritizes social connections and environmental goods over material consumption. The storyline then bifurcates again at the second branching point (Fig. 8), depending on how these two forces interact.

In the main "ecohumanist revolution scenario," these two forces combine in constructive ways: environmental movements use their social organizing power to compel multinational corporations to replace their directors and executives with new leaders who embrace ecohumanist principles. These corporations use their economic and political power to effect rapid cuts in emissions, deployment of large-scale CDR, and the dedication of vast areas of land to wilderness. Human populations and activities contract into a series of dense megacities.

In the "suboptimal situation scenario," however, the ecohumanist ethos exerts less influence. Multinational corporations invest heavily in CDR, but the continued influence of fossil fuel interests undermines efforts to cut emissions. Despite its widespread adoption, CDR cannot keep pace with emissions, leading to significant climate change. Ultimately, in the climate wars scenario, in response to the climate wars' destruction, societies adopt an ecohumanist ethos. This scenario ends in much the same place as the ecohumanist revolution scenario, but it gets there by a much darker, more destructive route in a typical collapse and reconstruct storyline.

\section{$S R M \& C D R$ group}

The SRM \& CDR group, whose seeds were SRM and CDR, universal basic income (UBI), and border walls, began with a near future in which the prevailing international order deteriorates as societies turn inward. Climate change intensifies through the 2040s, with impacts at the upper end of current projections. Wealthier societies try to buffer the impacts by expanding UBI programs at national and subnational levels, which accelerates the flow of climate migrants within and between countries. This prompts a backlash in which national and subnational jurisdictions erect physical and legal barriers to entry, exacerbating the decline of the international order. Regional deployment of SRM targets specific environmental threats, such as the bleaching of the Great Barrier Reef.

Here, the story bifurcates at branching point 1 (Fig. 9), depending on how well societies manage the transition toward a new global order. In the "coordinated city-states scenario," the turn toward smaller societies ushers in an era of community-based solidarity and cooperation. Even as the power of nation-states declines, transnational networks of city-states coordinate global climatemanagement efforts that combine emissions abatement, CDR, and a globally coordinated deployment of SRM to limit peak warming. In the "climate chaos scenario," however, conflict between city-states and between national and subnational jurisdictions prevents the rise of coordinated climate action. Efforts to deploy SRM are met with counter geoengineering (that is, technical measures to counteract SRM), and climate impacts continue to intensify at least through the end of the century.

The SRM \& CDR group also explored a wide range of subtle variations on these two scenarios, including one in response to a wild card, in which a climate doomsday cult enlists Bruce Willis to detonate a nuclear bomb inside the West Antarctic ice sheet to 
hasten sea-level rise. These are captured in the final Twine story that was developed by the group (https://bit.ly/2A8W0ch).

Fig. 9. A diagram of the two main branching pathways from the SRM \& CDR (solar radiation modification \& carbon dioxide removal) group. Each colored curve represents a different storyline, with the "branching points" marked with a red dot where the storyline bifurcates. The subtle variations that the SRM \& CDR group explored are not depicted here. Note that although the wild cards were important in getting the group to think about alternative futures, they were not incorporated into the final storylines.

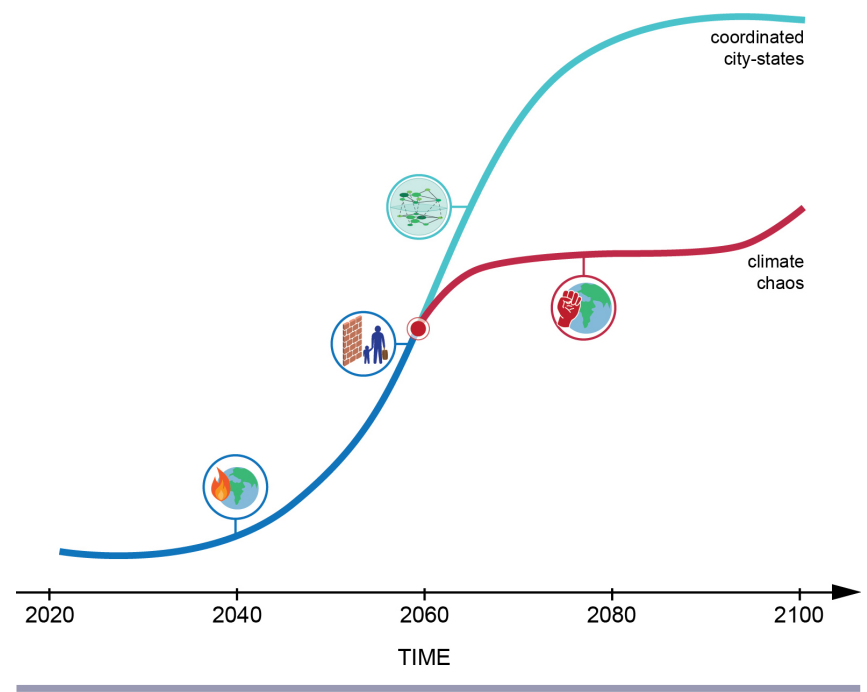

The key branching points and dynamics between the scenario families are captured in Table 4. It is important to highlight how social-political factors such as societal values, trust, and governance structures are pivotal points in all of the scenarios. Other ongoing trends like urbanization and adaptation also have impacts on the future scenarios depending on how they continue to play out. These are further unpacked in the discussion.

\section{DISCUSSION}

\section{Analyzing social-environmental dynamics influencing climate futures}

This workshop aimed to produce dynamic scenarios, in the sense that future events and trends provoke social responses that can feed back to change the direction of the scenarios. The process followed in the workshop also forced the explicit rendering of assumptions that the expert participants carried in their heads into the scenarios-generation exercise, and further, the consideration of the utility and veracity of assumptions within the building and branching of coherent worlds. Across all three scenario families, environmental changes drive social and political changes that dramatically change climate outcomes. Comparing the scenarios from each group revealed four important social and social-environmental dynamics that could influence how the next century unfolds. These dynamics, individually or jointly, played key roles both in the overall course of each scenario and in driving the branching within each of the scenario families. By opening up the scenario process to more integrative and creative narratives with the aim of incorporating feedbacks between social and environmental systems, the dynamics we identified link to important debates in the social science and social-ecological systems literature that have not yet been taken up widely by the quantitative integrated assessment model or climate modeling community. These findings also have implications for decision making, however, we focus on outcomes most relevant for the research community.

We discuss these four dynamics as potential drivers of climate futures, particularly of the branching of futures. Most branches occurred when a group envisioned different social or governance responses to one or more of these social or social-environmental dynamics. As such, the branching points can be seen to represent hypotheses about alternative futures based on differences in human behavior and social-environmental feedback dynamics. Although these dynamics might be familiar to disciplinary experts, many are not widely appreciated or in use in climate scenarios and climate modeling. We advocate that their importance can be further tested through a combination of increased empirical work on the social dynamics related to climate, and their inclusion into climate models that consider a richer set of social-environmental feedbacks. We note that social science related to alteration of attitudes, norms, incentives, and politics are precisely the fields that have received the least funding for climate-related research to date, with only $0.12 \%$ of all research funding spent on the social science of climate mitigation (Overland and Sovacool 2020). Our scenarios indicate this as a major gap for increased research effort.

Motivation to mitigate due to climate shocks:

In many of the scenarios, climate impacts, including but not limited to dramatic physical impacts with large, second-order social impacts, increase motivation to take climate action, either among elites, the general public, or both. Existing social scientific studies of this dynamic have returned mixed results (Hazlett and Mildenberger 2020), but at least some recent studies find that climate impacts can alter publics' and politicians' attitudes and voting behavior (Konisky et al. 2016, Gagliarducci et al. 2019, Baccini and Leemann 2020, Hazlett and Mildenberger 2020). The groups in this scenario exercise assumed that such dynamics would become stronger in the presence of harsher climate impacts, with the dynamic only coming to play a large role in climate politics later in the century. They typically envisioned this as motivating at least emissions abatement and adaptation. In most cases, it also involved SRM and/or CDR. In a few storylines, CDR or SRM undermined efforts to cut emissions. The scenarios in which this dynamic plays an important role, the groups typically envisioned the impact to be long-lasting because of pathdependent effects involving changes in technology (e.g., falling costs of renewables), power structures (e.g., the displacement of nation-states by city-states or corporations), or social values (e. g., the success of environmental movements or the widespread adoption of intrusive governance mechanisms). By contrast, many existing scenarios, including those in the shared socioeconomic pathways-representative concentration pathways (SSP-RCP) matrix currently used by climate modelers, omit such feedbacks so that climate policies and social structures evolve independently of the magnitude of climate change and climate impacts. However, such feedbacks have been shown to make a significant difference in modeled climate outcomes (Beckage et al. 2018). 


\section{Moral hazard:}

In several of the scenarios, the introduction of SRM or CDR or both, undermines other efforts to mitigate or adapt to climate change, often with significant implications for the evolution of the scenario. In each case where this moral hazard effect plays an important role, it counteracts the motivation to mitigate by weakening motivation to reduce emissions. Both the CDR group and the SRM \& CDR group envisioned alternative pathways in which either the moral hazard or motivation to mitigate dynamic dominated, creating branching points in both of those scenario families. The existence, strength, and even sign of the moral hazard effect remains highly uncertain, despite a fair amount of discussion in the literature (see Merk et al. 2016, Markusson et al. 2018, Raimi et al. 2019, Reynolds 2019). The scenarios we developed suggest that the timing of the introduction of SRM and CDR along with other environmental and social forces at play will matter to the strength of the moral hazard effect, especially for emissions abatement, because of path dependence in climate policies and context sensitivity of any moral hazard.

Social unrest, mediated by social protections:

Climate-induced social unrest plays a key role in many of the scenarios, from mid-century climate impacts in the CDR and SRM \& CDR groups' scenario families to post-termination impacts in the stumble \& scramble storyline. Social unrest or rising inequities, in turn, can influence motivation to take climate action (Klinsky and Winkler 2018), linking this dynamic to the dynamics discussed above. For instance, both the SRM and the SRM \& CDR groups envisioned SRM emerging in response to social unrest caused by climate impacts. The groups hypothesized that the extent of social unrest depends on how well societies protect vulnerable people against climate impacts. The rapidly developing literature on climate and conflict provides some support for this hypothesis (Jones et al. 2017, Koubi 2019, von Uexkull and Buhaug 2021), and performing a response to climate change may be important in maintaining regime legitimacy (Buck et al. 2020). Furthermore, societies' success in coping with social unrest plays a pivotal role in branching points for each of the scenario families by affecting who holds power, as well as the urgency and level of coordination in climate responses, determining whether a scenario evolves in a positive or negative direction. That multiple branching points in the scenario families identified social unrest as being an important dynamic driving alternative futures, but that there is limited literature on the role of social unrest in determining climate futures is in itself interesting and suggests a potential key knowledge gap for further research.

\section{Decreased trust in institutions:}

In several scenarios, climate impacts undermine trust in governance institutions. Specifically, publics lose trust in institutions, such as governments, that are supposed to protect them from the kinds of harms that climate impacts cause. The relationships between society-wide trust in institutions, risk perceptions, and public willingness to support climate action have been explored in social science literatures (see Smith and Mayer 2018, Kulin and Johansson Sevä 2021), lending credence to the notion that a dip in trust makes it harder for institutions to gain public backing for the implementation of climate policy. Our scenarios' development also hypothesized that declining trust in certain key institutions, when combined with increased motivation to mitigate, may cause people to invest greater trust and power in other institutions, such as local or non-state actors.

\section{Developing integrative, dynamic, and creative climate change scenarios}

\section{More integrative}

No single disciplinary approach is sufficient to capture major uncertainties of geoengineering futures. An example occurs when the direct costs of SRM are presumed to be low and SRM can act rapidly, economic impact models tend to utilize SRM to the maximum possible extent, ignoring governance challenges (Harding et al. 2020). Similarly, although the physical sciences can help explore uncertainties about how the climate would respond to SRM, crucial uncertainties about whether, when, or how SRM might be used can only be addressed through a social sciences perspective. Despite recognition that bridging natural and social science disciplines is essential to addressing climate change, there are inherent impediments to this, including a lack of willingness to engage among practitioners and the differential rewards systems in different fields (Mooney et al. 2013). There has been a perceived bias when it comes to how important certain types of information are for decision making that tends to favor quantitative over qualitative data and this can limit the realm of possibilities that scenarios explore (Obermeister 2017). For instance, climate model simulations that neglect governance challenges and imagine perfect technological control to answer physical science questions have had an outsize influence on what scientists and policymakers envisage as potential geoengineering futures, especially when the leap to quantitative modeling leaves behind the qualitative details of a scenario. As such, it was important to ensure that the resulting scenarios could talk to a wide range of disciplines without alienating any particular climate research group. The hope is that our scenarios might also encourage other groups either to make use of these narratives or to undertake their own participatory scenario process, so as to open up the possibility space of climate futures in research discourse and to be able to involve a wider set of perspectives and values to this existential discussion.

The development of narrative scenarios is a necessary first step to address these shortcomings because narratives can include diverse, complex, and internally consistent descriptions of alternative futures that are difficult to capture with quantitative models. Therefore, the process used in this project employs narratives as an inclusive starting point for levelling the playing field between quantitative and more qualitative disciplines. The resulting narratives do not predict any particular future, but rather present a set of alternative futures. The epistemological purpose of these forecasts and visions is to help us anticipate possibilities while inducing scepticism about claims that any particular possibility is inevitable (Sardar 2010). In addition, the social and social-environmental dynamics identified as driving branching in these scenarios can be viewed as hypothesized processes that can be included into systems dynamics models, which explicitly consider dynamic feedbacks between social and environmental systems (see Beckage et al. 2018, Donges et al. 2018). These could form the next generation of integrated assessment models, giving a richer understanding of alternative climate futures.

\section{More dynamic}

The dominant set of quantitative scenario narratives used to project future climate change, i.e., the combination of SSPs and RCPs, deliberately exclude considerations of how human emissions and adaptation behaviors change in response to climate 
change (van Vuuren et al. 2011, O'Neill et al. 2016, Riahi et al. 2017). Each quantified narrative is locked into a particular future. This approach, although useful for its intended purpose to structure climate change research, risks communicating to decision makers and the public that the future has a limited set of fixed pathways. In reality, greenhouse gas emissions will be driven by dynamic interactions between biophysical and human systems: human emissions drive climate change, altering the occurrence of extreme events, which in turn influences human perceptions of and responses to risk, including future emissions and climate change. These feedback processes are dynamic components of the Earth System that generate multiple alternative climate change futures, but they have been largely absent from climate change scenarios (Beckage et al. 2018). The inclusion of these climate-social feedbacks is crucial for understanding alternative climate change futures, especially the benefits and risks of geoengineering technologies. For instance, workshop participants considered how rapidly accumulating climate damages might affect societies' willingness to deploy SRM as a quick response to climate change and how SRM might in turn affect societies' motivation to cut greenhouse gas emissions.

Adding climate-social feedbacks introduces more uncertainty into the diverse set of possible futures, making it even more important that scenarios avoid the appearance of being predictions for decision makers. To explore the range of possible outcomes, we developed scenarios that allow for branching (that is, the future is not pre-determined, but rather that certain events could lead to multiple different end points) and identify key bifurcation points that could lead to very different futures (Wise et al. 2014). With this in mind, this workshop deliberately aimed to break out of the "conceptual flatland" of the 2 X 2 matrix approach (see Curry and Schultz 2009) used to generate the shared socioeconomic pathways. Instead, it produced sets of narrative scenarios that explore a wide range of possible futures that incorporate not just biophysical processes and social processes considered separately, but also social-environmental dynamics and feedbacks.

The main target audience for these narratives is the modeling community and the decision makers that rely on the outputs from these models to inform climate policy. Importantly from a quantitative modeling perspective, the scenario narratives identify key dynamics that cause branching between futures, highlighting a smaller set of processes as influential in determining different futures without trying to predict a particular future. This is important not only for modelers to understand, but also for decision makers to appreciate because they often rely on outcomes of quantitative models for informing climate policy. These and/ or similar climate-social dynamics could be identified as priorities for future research funding and can be included into a next generation of IAMs to generate branching points in climate futures as societal responses co-evolve with climate risks (see Beckage et al. 2018, Donges et al. 2020). Such an updated IAM framework would be more in line with the updated Intergovernmental Panel on Climate Change (IPCC) and policyrelevant definition of risk as resulting not just from physical climate impacts, but also from human adaptation and mitigation responses to climate change (such as CDR and SRM).

\section{More creative}

Scenarios can be powerful analytical tools for organizing the research community, but they can also engage publics and policymakers in thinking about the role geoengineering might play in the future (Mach and Field 2017). In particular, many stakeholders may find rich, creative, narrative scenarios more engaging than the mostly quantitative ones that function mainly to structure climate change research. The kind of rich detail that comes from narrative scenarios is especially important for engaging decision makers and raising the awareness of diverse publics because quantitative modeling requires abstracting away the details that matter most to local, near-term decision making (Mach and Field 2017). Being able to use the outcomes of scenario exercises not just in models, but to improve decision making and public engagement directly is about building anticipatory governance capacity (Vervoort and Gupta 2018). However, this requires an effective means of communicating the scenarios and especially what they demonstrate about the possibility of plural possible futures.

Using the branching narratives we have described, we created a choose-your-own adventure game called Survive the Century (https://survivethecentury.net/), which was played by over 15,000 people in the first two weeks of launching. The appeal of the game is that it makes the choices players face in determining the future explicit and allows them to explore the consequences of those choices as they travel down different branches of the scenarios. The game is linked with the En-ROAD climate simulator and also uses wild card climate shocks as surprises that players have to respond to. This game has even caught the attention of the Fridays for the Future movement with some of the authors sitting on a panel organized on $25^{\text {th }}$ July 2021 by the movement's Most Affected People and Areas group to discuss how creative story writing can shape our climate futures. This demonstrates how such creative processes are increasingly being recognized and are able to reach a wide audience of interested parties thereby raising awareness about the potential futures that the planet is facing and what could be done to shift onto a better path.

Another important creative component of the scenarios was the emphasis on science fiction in the narratives. Science fiction prototyping is an increasingly recognized method for combining the creativity of science-fiction writing with the rigor of science to showcase how the future could unfold (Milkoreit 2016, Merrie et al. 2018). Being able to tap into the imagination is an important skill when dealing with the future, especially with issues as politically charged as climate change and geoengineering (Pereira et al. 2019). Indeed, some science-fiction writers are already viewed as thinkers on climate change and geoengineering (e.g., Kim Stanley Robinson and NK Jemisin) and the journal Nature publishes science fiction regularly in a section entitled Nature Futures (Sullivan and Gee 2014, Gee and Sullivan 2018). By focusing on storytelling in the introduction to the workshop and also by having science-fiction authors in each of the teams to emphasize this creative storytelling component, our scenario narratives are quite radical and not something that would otherwise necessarily have been achieved by the researchers on their own. Second, by using the adapted Manoa Mash-up method that explicitly deviates from the $2 \times 2$ matrix approach, the narratives are not constrained by only focusing on the potential futures derived from intersecting drivers of change. As such, they 
are much richer and more creative, and arguably truer to experienced complexity, than current climate change scenarios.

\section{CONCLUSION}

We have described the novel contribution of the Manoa Mashup method to the space of climate futures. As well as this methodological contribution, the resulting narratives are also of interest in that they identify four key dynamics related to: motivation to mitigate, moral hazard, social unrest, and trust that can lead to very different futures and abilities to absorb surprise events. These dynamics combined with the method for generating branching scenarios that incorporate feedbacks between social and environmental systems constitute the most important contributions of the scenario process described here for future work.

Developing scenarios and modeling frameworks that consider both an array of SRM and CDR alternatives and important climate-social feedbacks in their potential deployment is crucial to help guide decisions on reducing risks from climate change. The set of scenarios generated in this exercise highlights the significant role that SRM and CDR could play in future climate policy, for better or for worse. The development of these scenarios holds lessons for scenario generation and for thinking about climate policy and the potential integration (or not) of SRM and CDR into climate change responses, as well as for thinking about climate futures more broadly. In particular, the ways in which climate-social dynamics lead to different storylines within each scenario family suggests that such dynamics deserve additional attention from interdisciplinary scientists and additional consideration in the generation and modeling of climate change scenarios. These dynamics (often feedbacks) are not currently included in quantitative analyses, such as in IAMs.

The process documented shows that the modified Manoa MashUp method offers a way to develop integrative, creative, and dynamic scenarios that illuminate climate-social dynamics and generate branching points while providing enough concrete detail to discourage the perception of scenarios as predictions of the future. This kind of scenario generation process serves different goals than the kind of process used to produce the SSPs. The SSPs help researchers explore different corners of a more narrowly defined parameter space, whereas the scenarios we presented help explore the climate-social dynamics leading to parts of a larger parameter space. Because the SSPs and other similar approaches divorce socioeconomic pathways from climate policy to provide consistent background socioeconomic conditions for climate policy scenarios, they necessarily ignore climate-social feedbacks. By contrast, those feedbacks naturally come to the fore in scenarios emerging from the modified Manoa Mash-Up method.

Future research into climate policy portfolios could build on these contributions by devising empirical studies to better quantify the key dynamics identified in the context of climate change and by developing methods to incorporate climate-social feedbacks into IAMs that explore possible climate futures. Incorporating these feedbacks may more credibly and coherently help to guide decisions on the possible role of SRM and CDR technologies in reducing risks from climate change. Qualitative social science research could also help develop institutions to manage or harness those feedbacks and dynamics. Another step would be to rerun the exercise, but with different configurations of the same seeds to make the final narratives more comparable. Although not necessarily creating novel stories, this process could allow for a more systematic exploration of the possible futures derived from the nine starting seeds and to see if new pathways emerge as different seeds are clashed. Future scenario exercises can also use different seeds to explore other climate futures. Unfortunately, with such a qualitative and participatory process, there is no way that all possible configurations can be addressed, but by analyzing different combinations of seeds, a more robust set of dynamics could also be ascertained, building on the four already identified through this process.

Understanding the social-environmental dynamics associated with transformative technologies such as some of those postulated for large-scale SRM or CDR is a priority for socialecological systems research and governance more generally. Although our final scenarios encapsulate only a part of the myriad potential futures that could unfold with the deployment of SRM or CDR, the explicit plurality of the outcomes helps to move toward more transdisciplinary approaches that adopt a much more open and nuanced perspective (Asayama et al. 2019). The insights from the scenario generation method presented could be applicable more widely to other emerging social-environmentaltechnical systems such as gene drives in which the potential ramifications for both social and ecological systems are large. The biodiversity research community is actively exploring more dynamic and creative scenario approaches for generating global futures for people and nature (Pereira et al. 2020). A similar move in this direction from the climate research community would create a strong opportunity for better integration of the next generation of biodiversity and climate futures to provide actionable insights for decision makers on these interlinked global challenges.

Responses to this article can be read online at: https://www.ecologyandsociety.org/issues/responses. php/12856

\section{Acknowledgments:}

We thank Brian O'Neill for presentations during the workshop. This work was supported by the National Socio-Environmental Synthesis Center (SESYNC) under funding received from the National Science Foundation DBI-1639145. Laura Pereira acknowledges that her research is supported in part by the National Research Foundation of South Africa (Grant Number 115300), the Swedish Research Council FORMAS Project No 2020-00670 and the CGIAR Research Program on Climate Change, Agriculture and Food Security (CCAFS) with funds provided by the CGIAR Fund Council, Australia (ACIAR), European Union, International Fund for Agricultural Development (IFAD), New Zealand, Netherlands, Switzerland, UK, and Thailand. Christopher Trisos acknowledges support from the FLAIR Fellowship Programme: a partnership between the African Academy of Sciences and the Royal Society funded by the UK Government's Global Challenges Research Fund. We acknowledge the helpful comments from anonymous reviewers 
that strengthened this manuscript significantly. A special thanks to Keren Cooper who helped with all the intricate table formatting and figure design.

\section{Data Availability:}

All available data are included in Appendix 1.

\section{LITERATURE CITED}

Asayama, S., M. Sugiyama, A. Ishii, and T. Kosugi. 2019. Beyond solutionist science for the Anthropocene: to navigate the contentious atmosphere of solar geoengineering. Anthropocene Review 6(1-2):19-37. https://doi.org/10.1177/2053019619843678

Atwood, M. 1985. The handmaid's tale. Vintage, London, U.K.

Baccini, L., and L. Leemann. 2020. Do natural disasters help the environment? How voters respond and what that means. Political Science Research and Methods 9:468-484. https://doi. org/10.1017/psrm.2020.25

Beck, S., and M. Mahony. 2017. The IPCC and the politics of anticipation. Nature Climate Change 7(5):311-313. https://doi. org/10.1038/nclimate3264

Beckage, B., L. J. Gross, K. Lacasse, E. Carr, S. S. Metcalf, J. M. Winter, P. D. Howe, N. Fefferman, T. Franck, A. Zia, A. Kinzig, and F. M. Hoffman. 2018. Linking models of human behaviour and climate alters projected climate change. Nature Climate Change 8(1):79-84. https://doi.org/10.1038/s41558-017-0031-7

Beukes, L., K. S. Robinson, K. Liu, H. Rajaniemi, A. Reynolds, and A. de Bodard. 2017. Science fiction when the future is now. Nature 552(7685):329-333. https://doi.org/10.1038/d41586-017-08674-8

Buck, H., O. Geden, M. Sugiyama, and O. Corry. 2020. Pandemic politics-lessons for solar geoengineering. Communications Earth and Environment 1(1):16. https://doi.org/10.1038/ s43247-020-00018-1

Costello, A., M. Abbas, A. Allen, S. Ball, S. Bell, R. Bellamy, S. Friel, N. Groce, A. Johnson, M. Kett, M. Lee, C. Levy, M. Maslin, D. McCoy, B. McGuire, H. Montgomery, D. Napier, C. Pagel, J. Patel, J. A. P. de Oliveira, N. Redclift, H. Rees, D. Rogger, J. Scott, J. Stephenson, J. Twigg, J. Wolff, and C. Patterson. 2009. Managing the health effects of climate change. Lancet and University College London Institute for Global Health Commission. Lancet 373(9676):1693-1733. https://doi.org/10.1016/ S0140-6736(09)60935-1

Curry, A., and W. Schultz. 2009. Roads less travelled: different methods, different futures. Journal of Futures Studies 13 (4):35-60. [online] URL: https://jfsdigital.org/wp-content/ uploads/2014/01/134-AE03.pdf

Diffenbaugh, N. S., and M. Burke. 2019. Global warming has increased global economic inequality. Proceedings of the National Academy of Sciences 116(20):9808-9813. https://doi. org/10.1073/pnas.1816020116

Donges, J. F., J. Heitzig, W. Barfuss, M. Wiedermann, J. A. Kassel, T. Kittel, J. J. Kolb, T. Kolster, F. Müller-Hansen, I. M. Otto, K. B. Zimmerer, and W. Lucht. 2018. Earth system modeling with endogenous and dynamic human societies: the copan:CORE open World-Earth modeling framework. Earth System Dynamics 11(2):395-413. https://doi.org/10.5194/esd-11-395-2020

Elsawah, S., S. H. Hamilton, A. J. Jakeman, D. Rothman, V. Schweizer, E. Trutnevyte, H. Carlsen, C. Drakes, B. Frame, B. Fu, C. Guivarch, M. Haasnoot, E. Kemp-Benedict, K. Kok, H. Kosow, M. Ryan, and H. van Delden. 2020. Scenario processes for socio-environmental systems analysis of futures: a review of recent efforts and a salient research agenda for supporting decision making. Science of the Total Environment 729:138393. https://doi.org/10.1016/j.scitotenv.2020.138393

Evans, A. 2017. The myth gap. Penguin Random House, London, U.K.

Floyd, J. 2012. Action research and integral futures studies: a path to embodied foresight. Futures 44(10):870-882. https://doi. org/10.1016/j.futures.2012.09.001

Gagliarducci, S., M. D. Paserman, and E. Patacchini. 2019. Hurricanes, climate change policies and electoral accountability. NBER Working Paper Series. National Bureau of Economic Research, Cambridge, Massachusetts, USA. https://doi. org/10.3386/w25835

Geden, O. 2016. The Paris Agreement and the inherent inconsistency of climate policymaking. Wiley Interdisciplinary Reviews: Climate Change 7(6):790-797. https://doi.org/10.1002/ wcc. 427

Gee, H., and C. Sullivan. 2018. Nature futures 2: science fiction from the leading science journal. TOR Books, New York, New York, USA.

Harding, A. R., K. Ricke, D. Heyen, D. G. MacMartin, and J. Moreno-Cruz. 2020. Climate econometric models indicate solar geoengineering would reduce inter-country income inequality. Nature Communications 11(1):227. https://doi.org/10.1038/ s41467-019-13957-X

Hazlett, C., and M. Mildenberger. 2020. Wildfire exposure increases pro-environment voting within Democratic but not Republican areas. American Political Science Review 114 (4):1359-1365. https://doi.org/10.1017/s0003055420000441

Hebinck, A., J. M. Vervoort, P. Hebinck, L. Rutting, and F. Galli. 2018. Imagining transformative futures: participatory foresight for food systems change. Ecology and Society 23(2):16. https:// doi.org/10.5751/ES-10054-230216

Hughes, T. P., K. D. Anderson, S. R. Connolly, S. F. Heron, J. T. Kerry, J. M. Lough, A. H. Baird, J. K. Baum, M. L. Berumen, T. C. Bridge, D. C. Claar, C. M. Eakin, J. P. Gilmour, N. A. J. Graham, H. Harrison, J.-P. A. Hobbs, A. S. Hoey, M. Hoogenboom, R. J. Lowe, M. T. McCulloch, J. M. Pandolfi, M. Pratchett, V. Schoepf, G. Torda, and S. K. Wilson. 2018. Spatial and temporal patterns of mass bleaching of corals in the Anthropocene. Science 359(6371):80-83. https://doi.org/10.1126/ science.aan 8048

Hulme, M. 2020. One Earth, many futures, no destination. One Earth 2:309-311. https://doi.org/10.1016/j.oneear.2020.03.005

Irvine, P., K. Emanuel, J. He, L. W. Horowitz, G. Vecchi, and D. Keith. 2019. Halving warming with idealized solar geoengineering moderates key climate hazards. Nature Climate Change 9(4):295-299. https://doi.org/10.1038/s41558-019-0398-8 
Jebari, J., O. O. Táíwò, T. M. Andrews, V. Aquila, B. Beckage, M. Belaia, M. Clifford, J. Fuhrman, D. P. Keller, K. J. Mach, D. R. Morrow, K. T. Raimi, D. Visioni, S. Nicholson, and C. H. Trisos. 2021. From moral hazard to risk-response feedback. Climate Risk Management 23:100324. https://doi.org/10.1016/j.crm.2021.100324

Jones, A. 2018. How a game prompted "the big talk" about geoengineering governance. C2G, 3 May. [online] URL: https:// www.c2g2.net/how-a-game-prompted-the-big-talk-about-geoengineeringgovernance/

Jones, B. T., E. Mattiacci, and B. F. Braumoeller. 2017. Food scarcity and state vulnerability: unpacking the link between climate variability and violent unrest. Journal of Peace Research 54(3):335-350. https://doi.org/10.1177/0022343316684662

Keller, D. P., A. Lenton, V. Scott, N. E. Vaughan, N. Bauer, D. Ji, C. D. Jones, B. Kravitz, H. Muri, and K. Zickfeld. 2018. The carbon dioxide removal model intercomparison project (CDRMIP): rationale and experimental protocol for CMIP6. Geoscientific Model Development 11(3):1133-1160. https://doi. org/10.5194/gmd-11-1133-2018

Klinsky, S., and H. Winkler. 2018. Building equity in: strategies for integrating equity into modelling for a $1.5^{\circ} \mathrm{C}$ world. Philosophical Transactions of the Royal Society 376:2119. https:// doi.org/10.1098/rsta.2018.0115

Konisky, D. M., L. Hughes, and C. H. Kaylor. 2016. Extreme weather events and climate change concern. Climatic Change 134 (4):533-547. https://doi.org/10.1007/s10584-015-1555-3

Koubi, V. 2019. Climate change and conflict. Annual Review of Political Science 22:343-360. https://doi.org/10.1146/annurevpolisci-050317-070830

Kravitz, B., A. Robock, O. Boucher, H. Schmidt, K. E. Taylor, G. Stenchikov, and M. Schulz. 2011. The Geoengineering Model Intercomparison Project (GeoMIP). Atmospheric Science Letters 12(2):162-167. https://doi.org/10.1002/asl.316

Kulin, J., and I. Johansson Sevä. 2021. Who do you trust? How trust in partial and impartial government institutions influences climate policy attitudes. Climate Policy 21:33-46. https://doi. org/10.1080/14693062.2020.1792822

Lin, A. C. 2013. Does geoengineering present a moral hazard. Ecology Law Quarterly 40. [online] URL: https://escholarship. org/uc/item/7th0d0pd

Long, J. C. S., and J. G. Shepherd. 2014. The strategic value of geoengineering research. Pages 757-770 in Bill Freedman, editor. Global environmental change. Springer, Amsterdam, The Netherlands https://doi.org/10.1007/978-94-007-5784-4 24

Lum, R. 2014. Working with Verge. APF Compass, April:5-8. [online] URL: https://ddtconference.files.wordpress.com/2017/07/ lum-verge-apfcompass-april14.pdf

Mach, K. J., and C. B. Field. 2017. Toward the next generation of assessment. Annual Review of Environment and Resources 42 (1):569-597. https://doi.org/10.1146/annurev-environ-102016-061007

MacMartin, D. G., and B. Kravitz. 2019. Mission-driven research for stratospheric aerosol geoengineering. Proceedings of the
National Academy of Sciences 116(4):1089-1094. https://doi. org/10.1073/pnas.1811022116

Markusson, N., D. McLaren, and D. Tyfield. 2018. Towards a cultural political economy of mitigation deterrence by negative emissions technologies (NETs). Global Sustainability 1(May): e10. https://doi.org/10.1017/sus.2018.10

Masys, A. J. 2012. Black swans to grey swans: revealing the uncertainty. Disaster Prevention and Management 21(3):320-335. https://doi.org/10.1108/09653561211234507

Merk, C., G. Pönitzsch, and K. Rehdanz. 2016. Knowledge about aerosol injection does not reduce individual mitigation efforts. Environmental Research Letters 11(5):054009. https://doi. org/10.1088/1748-9326/11/5/054009

Merrie, A., P. Keys, M. Metian, and H. Österblom. 2018. Radical ocean futures-scenario development using science fiction prototyping. Futures 95:22-32. https://doi.org/10.1016/j. futures.2017.09.005

Milkoreit, M. 2016. The promise of climate fiction: imagination, storytelling, and the politics of the future. Pages 171-191 in P. Wapner and H. Elver, editors. Reimagining climate change. Routledge, Oxford, UK.

Miller, R. 2013. Changing the conditions of change by learning to use the future differently. Pages 107-111 in World social science report. International Social Science Council, Paris, France. https://doi.org/10.1787/9789264203419-14-en

Mooney, H. A., A. Duraiappah, and A. Larigauderie. 2013. Evolution of natural and social science interactions in global change research programs. Proceedings of the National Academy of Sciences 110 Suppl 1(Supplement 1):3665-3672. https://doi. org/10.1073/pnas.1107484110

Moore, M.-L., and M. Milkoreit. 2020. Imagination and transformations to sustainable and just futures. Elementa: Science of the Anthropocene 8(1):081. https://doi.org/10.1525/elementa.2020.081

Morrow, D. R. 2014. Ethical aspects of the mitigation obstruction argument against climate engineering research. Philosophical Transactions of the Royal Society A 372(2031). https://doi. org/10.1098/rsta.2014.0062

Nature. 2018. Learn to tell science stories. Editorial. Nature, 7 March. https://doi.org/10.1038/d41586-018-02740-5

Obermeister, N. 2017. From dichotomy to duality: Addressing interdisciplinary epistemological barriers to inclusive knowledge governance in global environmental assessments. Environmental Science and Policy 68:80-86. https://doi.org/10.1016/j.envsci.2016.11.010

O’Neill, B. C., T. R. Carter, K. Ebi, P. A. Harrison, E. KempBenedict, K. Kok, E. Kriegler, B. L. Preston, K. Riahi, J. Sillmann, B. J. van Ruijven, D. van Vuuren, D. Carlisle, C. Conde, J. Fuglestvedt, C. Green, T. Hasegawa, J. Leininger, S. Monteith, and R. Pichs-Madruga. 2020. Achievements and needs for the climate change scenario framework. Nature Climate Change 10 (12):1074-1084. https://doi.org/10.1038/s41558-020-00952-0

O’Neill, B. C., E. Kriegler, K. L. Ebi, E. Kemp-Benedict, K. Riahi, D. S. Rothman, B. J. van Ruijven, D. P. van Vuuren, J. Birkmann, 
K. Kok, M. Levy, and W. Solecki. 2017. The roads ahead: narratives for shared socioeconomic pathways describing world futures in the 21 st century. Global Environmental Change 42:169-180. https://doi.org/10.1016/j.gloenvcha.2015.01.004

O’Neill, B. C., C. Tebaldi, D. P. van Vuuren, V. Eyring, P. Friedlingstein, G. Hurtt, R. Knutti, E. Kriegler, J.-F. Lamarque, J. Lowe, G. A. Meehl, R. Moss, K. Riahi, and B. M. Sanderson. 2016. The scenario model intercomparison project (ScenarioMIP) for CMIP6. Geoscientific Model Development 9(9):3461-3482. https://doi.org/10.5194/gmd-9-3461-2016

Overland, I., and B. K. Sovacool. 2020. The misallocation of climate research funding. Energy Research and Social Science 62:101349. https://doi.org/10.1016/j.erss.2019.101349

Pereira, L., K. Davies, E. den Belder, S. Ferrier, S. KarlssonVinkhuysen, H. Kim, J. Kuiper, S. Okayasu, M. G. Palomo, H. Pereira, G. Peterson, J. Sathyapalan, M. Schoolenberg, R. Alkemade, S. C. Ribeiro, A. Greenaway, J. Hauck, N. King, T. Lazarova, F. Ravera, N. Chettri, W. Cheung, R. Hendriks, G. Kolomytsev, P. Leadley, J. P. Metzger, K. Ninan, R. Pichs, A. Popp, C. Rondinini, I. Rosa, D. van Vuuren, and C. Lundquist. 2020. Developing multi-scale and integrative nature-people scenarios using the Nature Futures Framework. People and Nature :1-24. https://doi.org/10.31235/osf.io/ka69n

Pereira, L., J. J. Kuiper, O. Selomane, A. P. D. Aguiar, G. R. Asrar, E. M. Bennett, R. Biggs, K. Calvin, S. Hedden, A. Hsu, J. Jabbour, N. King, A. C. Köberle, P. Lucas, J. Nel, A. V Norström, G. Peterson, N. Sitas, C. Trisos, D. P. van Vuuren, J. Vervoort, and J. Ward. 2021. Advancing a toolkit of diverse futures approaches for global environmental assessments. Ecosystems and People 17 (1):191-204. https://doi.org/10.1080/26395916.2021.1901783

Pereira, L. M., T. Hichert, M. Hamann, R. Preiser, and R. Biggs. 2018. Using futures methods to create transformative spaces: visions of a good Anthropocene in southern Africa. Ecology and Society 23(1):19. https://doi.org/10.5751/es-09907-230119

Pereira, L., N. Sitas, F. Ravera, A. Jimenez-Aceituno, and A. Merrie. 2019. Building capacities for transformative change towards sustainability: imagination in intergovernmental sciencepolicy scenariopProcesses. Elementa Science of the Anthropocene 7(1):35. https://doi.org/10.1525/elementa.374

Proctor, J., S. Hsiang, J. Burney, M. Burke, and W. Schlenker. 2018. Estimating global agricultural effects of geoengineering using volcanic eruptions. Nature 560(7719):480-483. https://doi. org/10.1038/s41586-018-0417-3

Raimi, K. T., A. Maki, D. Dana, and M. P. Vandenbergh. 2019. Framing of geoengineering affects support for climate change mitigation. Environmental Communication 13(3):300-319. https://doi.org/10.1080/17524032.2019.1575258

Rana, S., D. Ávila-garcía, V. Dib, L. Familia, L. C. Gerhardinger, E. Martin, P. I. Martins, J. Pompeu, O. Selomane, J. I. Tauli, D. H. T. Tran, M. Valle, J. von Below, L. M. Pereira. 2020. The voices of youth in envisioning positive futures for nature and people. Ecosystems and People 16(1):326-344. https://doi. org/10.1080/26395916.2020.1821095

Raudsepp-Hearne, C., G. D. Peterson, E. M. Bennett, R. Biggs, A. V. Norström, L. Pereira, J. Vervoort, D. M. Iwaniec, T.
McPhearson, P. Olsson, T. Hichert, M. Falardeau, and A. Jiménez Aceituno. 2019. Seeds of good anthropocenes: developing sustainability scenarios for Northern Europe. Sustainability Science. https://doi.org/10.1007/s11625-019-00714-8

Rayner, S. 2016. What might Evans-Pritchard have made of two degrees? Anthropology Today 32(4):1-2. https://doi. org/10.1111/1467-8322.12263

Reynolds, J. L. 2019. The governance of solar geoengineering: managing climate change in the Anthropocene. Cambridge University Press, New York, New York, USA. https://doi. org/10.1017/9781316676790

Riahi, K., D. P. van Vuuren, E. Kriegler, J. Edmonds, B. C. O'Neill, S. Fujimori, N. Bauer, K. Calvin, R. Dellink, O. Fricko, W. Lutz, A. Popp, J. C. Cuaresma, S. KC, M. Leimbach, L. Jiang, T. Kram, S. Rao, J. Emmerling, K. Ebi, T. Hasegawa, P. Havlik, F. Humpenöder, L. A. Da Silva, S. Smith, E. Stehfest, V. Bosetti, J. Eom, D. Gernaat, T. Masui, J. Rogelj, J. Strefler, L. Drouet, V. Krey, G. Luderer, M. Harmsen, K. Takahashi, L. Baumstark, J. C. Doelman, M. Kainuma, Z. Klimont, G. Marangoni, H. LotzeCampen, M. Obersteiner, A. Tabeau, and M. Tavoni. 2017. The shared socioeconomic pathways and their energy, land use, and greenhouse gas emissions implications: an overview. Global Environmental Change 42:153-168. https://doi.org/10.1016/j. gloenvcha.2016.05.009

Ricke, K. L., J. B. Moreno-Cruz, and K. Caldeira. 2013. Strategic incentives for climate geoengineering coalitions to exclude broad participation. Environmental Research Letters 8(1):014021. https://doi.org/10.1088/1748-9326/8/1/014021

Roelfsema, M., H. L. van Soest, M. Harmsen, D. P. van Vuuren, C. Bertram, M. den Elzen, N. Höhne, G. Iacobuta, V. Krey, E. Kriegler, G. Luderer, K. Riahi, F. Ueckerdt, J. Després, L. Drouet, J. Emmerling, S. Frank, O. Fricko, M. Gidden, F. Humpenöder, D. Huppmann, S. Fujimori, K. Fragkiadakis, K. Gi, K. Keramidas, A. C. Köberle, L. Aleluia Reis, P. Rochedo, R. Schaeffer, K. Oshiro, Z. Vrontisi, W. Chen, G. C. Iyer, J. Edmonds, M. Kannavou, K. Jiang, R. Mathur, G. Safonov, and S. S. Vishwanathan. 2020. Taking stock of national climate policies to evaluate implementation of the Paris Agreement. Nature Communications 11(1):2096. https://doi.org/10.1038/s41467-020-15414-6

Rogelj, J., A. Popp, K. V. Calvin, G. Luderer, J. Emmerling, D. Gernaat, S. Fujimori, J. Strefler, T. Hasegawa, G. Marangoni, V. Krey, E. Kriegler, K. Riahi, D. P. Van Vuuren, J. Doelman, L. Drouet, J. Edmonds, O. Fricko, M. Harmsen, P. Havlík, F. Humpenöder, E. Stehfest, and M. Tavoni. 2018. Scenarios towards limiting global mean temperature increase below $1.5^{\circ} \mathrm{c}$. Nature Climate Change 8(4):325-332. https://doi.org/10.1038/ $\underline{\text { s41558-018-0091-3 }}$

Saltelli, A., G. Bammer, I. Bruno, E. Charters, M. Di Fiore, E. Didier, W. N. Espeland, J. Kay, S. Lo Piano, D. Mayo, R. Pielke, Jr., T. Portaluri, T. M. Porter, A. Puy, J. R. Ravetz, E. Reinert, D. Sarewitz, P. B. Stark, A. Stirling, J. van der Sluijs, and P. Vineis. 2020. Five ways to ensure that models serve society: a manifesto. Nature 582:482-484. https://doi.org/10.1038/d41586-020-01812-9

Sardar, Z. 2010. The namesake: futures; futures studies; futurology; futuristic; foresight- what's in a name? Futures 42 (3):177-184. https://doi.org/10.1016/j.futures.2009.11.001 
Schipper, E. L. F., S. E. Eriksen, L. R. Fernandez Carril, B. C. Glavovic, and Z. Shawoo. 2021. Turbulent transformation: abrupt societal disruption and climate resilient development. Climate and Development 13(6):467-474. https://doi.org/10.1080/17565$\underline{529.2020 .1799738}$

Schultz, W. 2015. Manoa: the future is not binary. APF Compass April:22-26. [online] URL: https://www.academia.edu/12075841/ Manoa The future is not binary

Sharpe, B., A. Hodgson, G. Leicester, A. Lyon, and I. Fazey. 2016. Three horizons: a pathways practice for transformation. Ecology and Society 21(2):47. https://doi.org/10.5751/ES-08388-210247

Shepherd, T. G., E. Boyd, R. A. Calel, S. C. Chapman, S. Dessai, I. M. Dima-West, H. J. Fowler, R. James, D. Maraun, O. Martius, C. A. Senior, A. H. Sobel, D. A. Stainforth, S. F. B. Tett, K. E. Trenberth, B. J. J. M. van den Hurk, N. W. Watkins, R. L. Wilby, and D. A. Zenghelis. 2018. Storylines: an alternative approach to representing uncertainty in physical aspects of climate change. Climatic Change 151(3-4):555-571. https://doi.org/10.1007/ $\underline{\text { s10584-018-2317-9 }}$

Smith, E. K., and A. Mayer. 2018. A social trap for the climate? Collective action, trust and climate change risk perception in 35 countries. Global Environmental Change 49:140-153. https://doi. org/10.1016/j.gloenvcha.2018.02.014

Steinmüller, K. 2004. The future as wildcard. Pages 193-202 in S. Brockett and M. Dahlström, editors. Spatial development trends: Nordic countries in a European Context. Nordregio, Stockholm, Sweden. [online] URL: https://archive.nordregio.se/en/Publications/ Publications-2004/Spatial-Development-Trends-Nordic-Countriesin-a-European-Context/index.html

Sugiyama, M., Y. Arino, T. Kosugi, A. Kurosawa, and S. Watanabe. 2017. Next steps in geoengineering scenario research: limited deployment scenarios and beyond. Climate Policy 18 (6):681-689. https://doi.org/10.1080/14693062.2017.1323721

Sullivan, C., and H. Gee. 2014. Nature futures: science fiction from the leading science journal. TOR Books, New York, New York, USA.

Taleb, N. N. 2007. The black swan: the impact of the highly improbable. Penguin, London, U.K.

Tilmes, S., J. H. Richter, B. Kravitz, D. G. MacMartin, M. J. Mills, I. R. Simpson, A. S. Glanville, J. T. Fasullo, A. S. Phillips, J.-F. Lamarque, J. Tribbia, J. Edwards, S. Mickelson, and S. Ghosh. 2018. CESM1(WACCM) stratospheric aerosol geoengineering large ensemble project. Bulletin of the American Meteorological Society 99(11):2361-2371. https://doi.org/10.1175/bams-d-17-0267.1

Trisos, C. H., G. Amatulli, J. Gurevitch, A. Robock, L. Xia, and B. Zambri. 2018. Potentially dangerous consequences for biodiversity of solar geoengineering implementation and termination. Nature Ecology and Evolution 2(3):475-482. https:// doi.org/10.1038/s41559-017-0431-0

van Vuuren, D. P., J. Edmonds, M. Kainuma, K. Riahi, A. Thomson, K. Hibbard, G. C. Hurtt, T. Kram, V. Krey, J.-F. Lamarque, T. Masui, M. Meinshausen, N. Nakicenovic, S. J. Smith, and S. K. Rose. 2011. The representative concentration pathways: an overview. Climatic Change 109(1-2):5. https://doi. org/10.1007/s10584-011-0148-Z
Vervoort, J., and A. Gupta. 2018. Anticipating climate futures in a $1.5^{\circ} \mathrm{C}$ era: the link between foresight and governance. Current Opinion in Environmental Sustainability 31(February):104-111. https://doi.org/10.1016/j.cosust.2018.01.004

von Uexkull, N., and H. Buhaug. 2021. Security implications of climate change: A decade of scientific progress. Journal of Peace Research 58(1):3-17. https://doi.org/10.1177/0022343320984210

Voros, J. 2017. Big history and anticipation: using big history as a framework for global foresight. Pages 1-40 in R. Poli, editor. Handbook of anticipation. Springer, Cham, Switzerland.

Wise, R. M., I. Fazey, M. Stafford Smith, S. E. Park, H. C. Eakin, E. R. M. Archer Van Garderen, and B. Campbell. 2014. Reconceptualising adaptation to climate change as part of pathways of change and response. Global Environmental Change 28:325-336. https://doi.org/10.1016/j.gloenvcha.2013.12.002 


\section{"From fAIrplay to Climate Wars" Supplementary Material: Additional Details about the Workshop Process}

This Supplementary Material describes further details of the workshop process described in the main text, including demographic information about the participants, details about the ice breakers that facilitators used to set the stage for successful interdisciplinary collaboration, the VERGE framework that participants used to develop their narratives, and the performances by which each group presented their work to the other participants.

\section{Introductory Presentations and Ice-Breaking Games}

Participants spent the first half-day of the workshop playing and learning about the structure of a good narrative and the current paradigm for climate change scenarios,

After some brief introductory remarks from the organizers, three science fiction writers in the group opened the workshop with a lesson on the structure of a good narrative. This immediately conveyed the message that the workshop will not follow the typical pattern of an academic meeting.

They followed this with an ice-breaker designed to bring people out of disciplinary silos: they asked participants to introduce themselves not by their position or discipline, but by describing what they would do if the group were stranded on a desert island together. As an illustration, some participants suggested they could survey the landscape and find food, others suggested that they would try to identify the most powerful person and provide an analysis of how best to make decisions.

Building on this ice-breaker, they illustrated the content of their lesson on narratives by leading the group through a game called "fortunately, unfortunately." The game involves collaboratively concocting a story in which each person's contribution begins, alternately, with 'fortunately' or 'unfortunately'. In this case, the story focused on the group's experience on the hypothetical desert island.

After these ice breakers, Brian O'Neill of the University of Denver gave a remote presentation on the dominant scenario paradigm in climate science and climate policy, which combines the Shared Socioeconomic Pathways with Representative Concentration Pathways. 
For the final group exercise, Andrew Jones of Climate Interactive led participants through a game developed by Pablo Suarez of the Red Cross Red Crescent Climate Centre. The game, which is a variation of the Climate Centre's "Decisions for the Decade" game, uses a set of dice to simulate extreme events
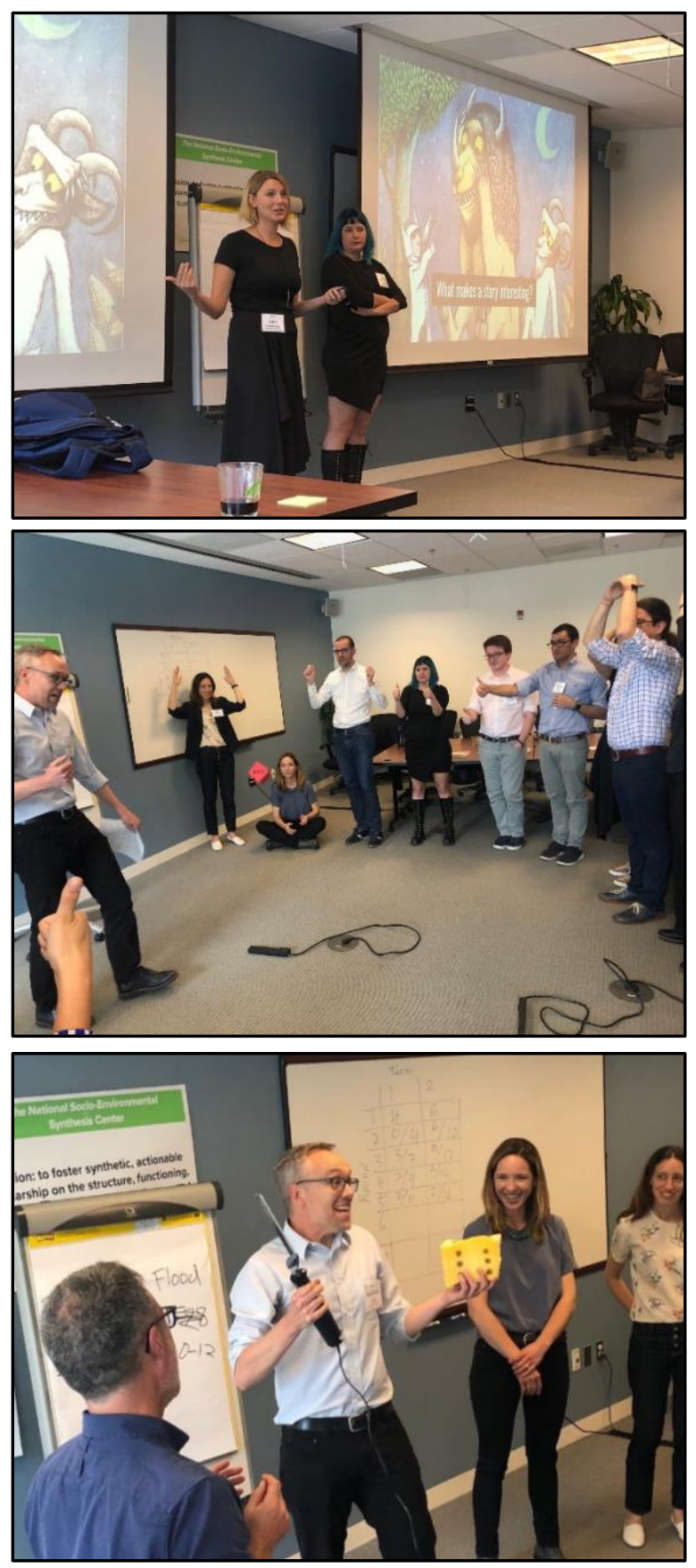

hitting different communities and introduces the possibility of using an electric knife to alter those dice, if the groups so desire. The result was a rugby maul between the two competing groups that definitely broke down barriers and resulted in a reflection session amongst all the participants as to how their decisions and actions resulted in the complete breakdown of the game. These introductory processes set up the creative and interactive foundations for the rest of the workshop.

Overall, the introductory session played an important role in setting the collaborative, transdisciplinary, and highly unorthodox tone for the workshop (Fig A1).

Fig. A1. Selected ice breakers from the workshop. Top: Sam Beckbesinger (left) and Lauren Beukes coach participants on good storytelling. Bottom left: Participants playing a variation of the Decisions for the Decade game. Bottom right: Andrew Jones (center, with electric knife) offers participants the chance to use technology to try to change the probability of certain outcomes in the Decisions for the Decade game. 


\section{VERGE Framework for Developing Narratives}

The groups used the questions in Table A1 as prompts for filling in the details of their imagined futures. Table A2, on the next page, synthesizes their responses to these prompts.

Table A1: Core questions posed to each group to describe their visions.

\begin{tabular}{|c|c|}
\hline $\begin{array}{l}\text { DOMAIN OF } \\
\text { EXPERIENCE }\end{array}$ & QUESTIONS \\
\hline $\begin{array}{l}\text { Worldviews, paradigms, } \\
\text { social values and } \\
\text { attitudes }\end{array}$ & $\begin{array}{l}\text { - What do people value? } \\
\text { - How do people spend their time? } \\
\text { - Human rights? } \\
\text { - Is there a focus on the individual or the collective/community? } \\
\text { - How many people are in the world? }\end{array}$ \\
\hline Adaptation & $\begin{array}{l}\text { - How do people respond to climate risks? } \\
\text { - Finance \& Insurance? }\end{array}$ \\
\hline $\begin{array}{l}\text { Family structures, } \\
\text { governance structures }\end{array}$ & $\begin{array}{l}\text { - Who is governing? Who makes the rules and takes decisions? } \\
\text { - Who has a voice? Who doesn't? } \\
\text { - How equal is society? What inequalities exist? (gender, poverty...) } \\
\text { - How are the most vulnerable treated (e.g., social protections)? }\end{array}$ \\
\hline Connections & $\begin{array}{l}\text { - How connected are people to each other? } \\
\text { - Are people connected to nature? How do they connect? } \\
\text { - How are people distributed (urban - rural)? } \\
\text { - How do people move? How much? Internal and int'I movement. } \\
\text { - What does trade of goods, services and ideas look like? } \\
\text { - What do transport networks look like? }\end{array}$ \\
\hline $\begin{array}{l}\text { Manufacturing, } \\
\text { art \& culture }\end{array}$ & $\begin{array}{l}\text { - What is the role of technology? (health, infrastructure, agriculture...) } \\
\text { - What are people making? }\end{array}$ \\
\hline Energy \& Economy & $\begin{array}{l}\text { - Where does energy come from (fossil fuels/ renewables/other)? } \\
\text { - Who controls the market? } \\
\text { - Where do people work? } \\
\text { - What work do they do? } \\
\text { - How do they get to work? } \\
\text { - Why do people work? }\end{array}$ \\
\hline $\begin{array}{l}\text { Environment } \\
\text { (built/natural) }\end{array}$ & $\begin{array}{l}\text { - What do landscapes/seascapes look like? } \\
\text { - Where is biodiversity? How much is there? } \\
\text { - What do cities look like? } \\
\text { - What do people look like? }\end{array}$ \\
\hline $\begin{array}{l}\text { Destruction } \\
\text { Violence, killing, waste, } \\
\text { undermining rules/norms }\end{array}$ & $\begin{array}{l}\text { - What happens to waste? } \\
\text { - How do people deal with conflict? } \\
\text { - How likely is violent conflict? Why and amongst whom? }\end{array}$ \\
\hline Food, Energy, Health & $\begin{array}{l}\text { - What do people eat? } \\
\text { - Where does food come from? } \\
\text { - Where does water come from? Is there water security? } \\
\text { - Are people healthy? } \\
\text { - What is the state of mental health? } \\
\text { - How do people recreate? }\end{array}$ \\
\hline
\end{tabular}


Table A2. Synthesis of Groups' Responses to VERGE Questions. Bold-faced abbreviations refer to specific scenarios within each scenario family (CC: climate chaos; CCS: coordinated citystates; $\boldsymbol{C C}$ : climate chaos; $\boldsymbol{C W}$ : climate wars; $\boldsymbol{E A}$ : eco-autocracy; FP: fAIrplay; SOS: suboptimal situation; SS: stumble \& scramble). Text not prefaced by a bold-faced abbreviation applies to all scenarios within the relevant scenario family.

\begin{tabular}{|c|c|c|c|}
\hline & SRM\&CDR & SRM & CDR \\
\hline$\frac{\dddot{y}}{\frac{\pi}{\pi}}$ & $\begin{array}{l}\text { CCS: Climate management as } \\
\text { a shared value, allowing for } \\
\text { technology-driven climate } \\
\text { action } \\
\text { Localized solidarity; global } \\
\text { connection } \\
\text { CC: Doomsday cultism; retreat } \\
\text { of liberal freedoms }\end{array}$ & $\begin{array}{l}\text { Human rights are subordinate } \\
\text { to algorithmic best decision- } \\
\text { making. Little privacy. } \\
\text { EA: Focus on community over } \\
\text { individual. }\end{array}$ & $\begin{array}{l}\text { Variations on ecohumanism } \\
\text { becomes dominant ethos: a } \\
\text { view of the good life that } \\
\text { combines valuing nature for } \\
\text { its inherent value with an } \\
\text { emphasis on social well-being } \\
\text { rather than profit and } \\
\text { material consumption. } \\
\text { sos: continued pursuit of } \\
\text { convenience, material } \\
\text { consumption; less emphasis } \\
\text { on nature }\end{array}$ \\
\hline 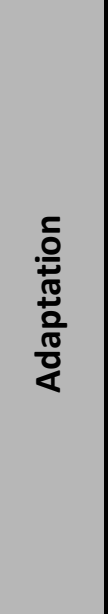 & $\begin{array}{l}\text { Localized forms of adaptation } \\
\text { in the face of climate risks and } \\
\text { climate shocks is one of the } \\
\text { drivers of increased place- } \\
\text { based and identity-based } \\
\text { forms of solidarity }\end{array}$ & $\begin{array}{l}\text { EA: High adaptation to } \\
\text { medium climate change. } \\
\text { SS: Legacy of adaptation from } \\
\text { BRI, but it's seriously } \\
\text { insufficient post-termination. } \\
\text { FP: Legacy of adaptation from } \\
\text { BRI; Global South better } \\
\text { adapted than North b/c of } \\
\text { newer infrastructure. We can } \\
\text { predict climate well, but how } \\
\text { much do we want to interfere } \\
\text { with it? (This sets adaptation } \\
\text { goals.) }\end{array}$ & $\begin{array}{l}\text { High capacity for adaptation } \\
\text { and loss \& damage finance; } \\
\text { climate change under control, } \\
\text { but sea-level rise continues. }\end{array}$ \\
\hline 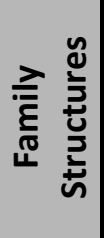 & $\begin{array}{l}\text { Not looked at explicitly. Place- } \\
\text { based forms of solidarity } \\
\text { spring up, suggesting tight } \\
\text { family units and family-based } \\
\text { connectedness }\end{array}$ & $\begin{array}{l}\text { Economic growth has reduced } \\
\text { population growth. }\end{array}$ & $\begin{array}{l}\text { Extended families tend to live } \\
\text { in close proximity in most city- } \\
\text { states. }\end{array}$ \\
\hline
\end{tabular}


Strong local management of decisions

Cities and subnational units; but strong interconnection so that coordination possible Extremely distributed Increased participation and direct democracy

More participation of women across decisionmaking

Federal governmental and intergovernmental institutions face challenges in the face of climate shocks, migration pressures, rise of "walls" (not just physical structures but policing of borders by drones etc; also rise of new forms of citizenship - e.g. need a New York City or New York State or "I work for Amazon" identity card to access localized benefits, including localized forms of UBI and the ability to live in certain places).

Intergovernmental

institutions and states COULD remain strong. This becomes a pivot point in our story.

Strong states and international institutions could facilitate global cooperation even as smaller sub-national units take or are granted more power. OR states could make a grab for maintenance of power leading to internal clashes (e.g. US federal government clashing with leadership and citizenry of New New Amsterdam) and increased level of international tension
People defer to $\mathrm{Al}$ in governance decisions.

FP: Al is nationalized, so tech companies do not have free rein. UN has major regional blocs on reformed SC, which may include large corporations.

EA: Nation-states exist but act in line with targets from global ecoautocracy.
Big 20 Corporations control $80 \%$ of Gross World Product, have taken over most government functions. Economically interconnected city-states have replaced nation-states because of geographic isolation. Equity in corporations broadly distributed. Inequality is relatively low both between and (especially) within citystates. 
Localized forms of solidarity. Strong sense of community. Increased happiness. Compassion and shared values means maintaining connection between and among units.

Less mobility. People can't (and don't necessarily want) to move as much.

Much reduced physical trade. $3 \mathrm{D}$ printing enables ideas rather than goods to be shared more easily; localized forms of solidarity and automation mean that much more can be done and experienced in local areas.

Building up of "walls" in the earlier part of the century gave negative pressures in the same direction, making mobility more difficult as UBI and other benefits of citizenship given just to those in particular areas; keep out those who don't belong.

CC: Above COULD give rise to xenophobic backlash and help push the descent into a darker world. OR xenophobia could be held in check in many places as those living in cities with UBI hold on to virtual connections and values of climate management coupled with place-based solidarity enable coordination even in the face of dispersed governance units
SS: Regional blocs of varying power. Cheap internet everywhere, but strict migration controls between blocs.

FP: ???

EA: World is extremely connected via virtual reality but people travel less; strict quota on flights.
Extended families and social circles are important.

Population density is bimodal, with many people living in dense "jungle cities" and the rest in the sparsely populated surrounding rural areas. Modal and fuel shifts in transport have all but eliminated transportation emissions. Technology facilitates international communication and tourism. 
Communications technologies and (perhaps) 3D printing at large-scale, along with workable forms of carbon capture and utilization, are keys in this world. People stay put for the most part but can still derive many of the benefits of mobility by sharing ideas and experiences with others far away and 3D printing rather than trade in goods

Even those who are outside localized systems of UBI are able to tap into the connected carbon economy (carbon is pulled out of the atmosphere and into storage or use because the shared ethic of climate management demands it, and these acts are able to be coordinated to an extent because of economic motivations and the ability for distributed city and state governments to coordinate activities that have common benefit - a radical form of distributed global governance).
$\mathrm{Al}$ is pervasive. Manufacturing is highly automated.

EA: Entertainment is produced/condoned by ecoautocracy.
Mostly globalized production of goods using zero-carbon energy, complemented by local "boutique businesses." 


\begin{tabular}{|c|c|c|c|}
\hline & SRM\&CDR & SRM & CDR \\
\hline 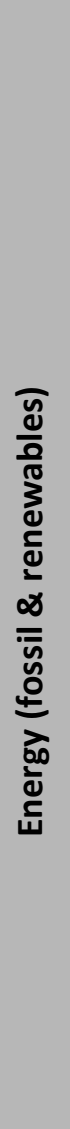 & $\begin{array}{l}\text { ENERGY } \\
\text { A lot of carbon-free energy } \\
\text { substantially deployed } \\
\text { Lots of CDR deployed } \\
\text { Small amount of SRM } \\
\text { Some remaining fossil fuel; } \\
\text { other climate forcers from } \\
\text { agriculture etc } \\
\text { ECONOMY } \\
\text { Decentralized; lots of socially } \\
\text { beneficial jobs. } \\
\text { UDI removing pressure to do } \\
\text { jobs just for money itself } \\
\text { Circular carbon economy } \\
\text { More trade in ideas and } \\
\text { blueprints; less trade in } \\
\text { physical goods } \\
\text { (3D printing implemented) }\end{array}$ & $\begin{array}{l}\text { SS: Energy production is } \\
\text { regionalized. So is SRM. } \\
\text { Confidence in renewables is } \\
\text { reduced because of } \\
\text { interference from SRM in } \\
\text { other regions. Legacy of } \\
\text { renewable and fossil } \\
\text { infrastructure from pre- } \\
\text { climate-emergency. } \\
\text { FP: Decentralized energy w/ } \\
\text { high renewables, including } \\
\text { large-scale hydro from BRI. On } \\
\text { the way to net-negative. } \\
\text { Some fossil fuels from BRI } \\
\text { legacy. Fossil interests using } \\
\text { fact of SAl to resist complete } \\
\text { phase-out. Discussion of dam } \\
\text { deconstruction. } \\
\text { EA: Centralized renewables } \\
\text { w/ int'l electricity grids. Al has } \\
\text { increased efficiency, reduced } \\
\text { costs of renewables b/c of } \\
\text { improved forecasts (weather, } \\
\text { energy demand). }\end{array}$ & $\begin{array}{l}\text { Ninety percent of energy } \\
\text { comes from zero-carbon } \\
\text { energy sources, with residual } \\
\text { emissions (more than) } \\
\text { compensated for by CDR. } \\
\text { SOS: high residual emissions } \\
\text { from fossil fuels, offset by } \\
\text { large-scale CDR }\end{array}$ \\
\hline 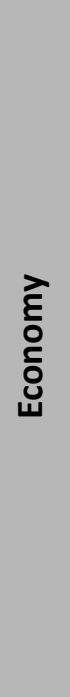 & $\begin{array}{l}\text { Some addition local and } \\
\text { regional biodiversity and } \\
\text { landscape protection as } \\
\text { people have more leisure (UBI } \\
+ \text { automation), spurring } \\
\text { increased attention to looking } \\
\text { after local landscapes } \\
\text { Uncertain whether major } \\
\text { hotspots of biodiversity are } \\
\text { able to survive mid-century } \\
\text { climate shocks, human } \\
\text { migration, and resource grabs. } \\
\text { Cities are new loci of political } \\
\text { power and adaptation in the } \\
\text { face of climate change }\end{array}$ & $\begin{array}{l}\text { Al economy. Al-induced job } \\
\text { losses prompt widespread } \\
\text { UBI. Good infrastructure } \\
\text { across Global South. } \\
\text { EA: Mining of moon and } \\
\text { asteroids by machines. }\end{array}$ & $\begin{array}{l}\text { Most people work for the Big } \\
\text { Corporations, while some } \\
\text { work for local "boutique } \\
\text { businesses." In most city- } \\
\text { states, people choose their } \\
\text { own hours and work part-time } \\
\text { to get some money, } \\
\text { contribute to society, and/or } \\
\text { engage in fulfilling projects. }\end{array}$ \\
\hline
\end{tabular}




\begin{tabular}{|c|c|c|c|}
\hline & SRM\&CDR & SRM & CDR \\
\hline 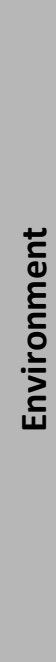 & $\begin{array}{l}\text { More interest in place-based } \\
\text { preservation } \\
\text { Turn to technology, though, } \\
\text { severing connections with } \\
\text { self-willed nature; dominant } \\
\text { ethos of management and } \\
\text { control }\end{array}$ & $\begin{array}{l}\text { Mass extinctions. } \\
\text { EA: Massive carbon forest } \\
\text { preserves, optimized for } \\
\text { carbon storage, not } \\
\text { biodiversity. } \\
\text { SS \& FP: Legacy of } \\
\text { deforestation from BRI. }\end{array}$ & $\begin{array}{l}\text { Much of the land is given over } \\
\text { to wilderness, punctuated by } \\
\text { large rural areas centered } \\
\text { around dense, high-rise } \\
\text { "jungle cities." Biodiversity is } \\
\text { high in higher latitudes but } \\
\text { remains severely damaged at } \\
\text { lower latitudes, where } \\
\text { massive ecological restoration } \\
\text { efforts are underway. Marine } \\
\text { biodiversity has declined } \\
\text { significantly, especially in the } \\
\text { tropics, but restoration efforts } \\
\text { are underway there, too. }\end{array}$ \\
\hline 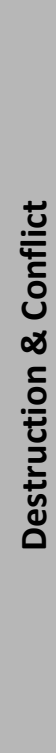 & $\begin{array}{l}\text { CCS: Conflict relatively } \\
\text { unlikely, as solidarity within } \\
\text { city-states and cooperation } \\
\text { between city-states } \\
\text { predominate. } \\
\text { CC: Violent conflict quite } \\
\text { likely. }\end{array}$ & $\begin{array}{l}\text { SS: Flash wars started and } \\
\text { completed by algorithms, } \\
\text { sometimes in minutes, often } \\
\text { over disagreement about } \\
\text { regional SRM. Disruption from } \\
\text { climate refugees, especially } \\
\text { SIS and countries unable to } \\
\text { deploy regional SRM (e.g., } \\
\text { inland countries). } \\
\text { EA: Strong rule enforcement } \\
\text { through shaming and } \\
\text { ostracization linked to } \\
\text { ecocredit score. }\end{array}$ & $\begin{array}{l}\text { Social conflict persists over } \\
\text { the dominant ecohumanist } \\
\text { ethos, especially between } \\
\text { ecohumanist city-states and } \\
\text { those that reject the ethos for } \\
\text { one reason or another. } \\
\text { CW: a series of devastating } \\
\text { wars kill a significant } \\
\text { percentage of global } \\
\text { population and destroy a huge } \\
\text { amount of economic } \\
\text { infrastructure in the late } 21 \text { st } \\
\text { century, leading to strongly } \\
\text { pacifist attitudes by the end of } \\
\text { the century. }\end{array}$ \\
\hline $\begin{array}{l}\text { 운 } \\
\text { 운 }\end{array}$ & $\begin{array}{l}\text { Localized, highly efficient } \\
\text { forms of production through } \\
\text { embrace of genetic } \\
\text { modification technologies and } \\
\text { methods allowing } \\
\text { intensification }\end{array}$ & $\begin{array}{l}\text { EA (All?): Reduced meat } \\
\text { consumption; plant-based } \\
\text { meat substitutes. Lots of fish } \\
\text { and seaweed from Chinese- } \\
\text { led aquaculture. } \\
\text { EA: Meat is boutique good. } \\
\text { Hunting in carbon preserves } \\
\text { by permit. }\end{array}$ & $\begin{array}{l}\text { Food systems are dominated } \\
\text { by local production, with } \\
\text { people eating primarily } \\
\text { seasonal foods. Food is grown } \\
\text { in rural areas surrounding } \\
\text { dense cities, where farmers } \\
\text { employ soil carbon-building } \\
\text { agricultural practices and } \\
\text { agroforestry. }\end{array}$ \\
\hline
\end{tabular}




\begin{tabular}{|c|c|c|c|}
\hline & SRM\&CDR & SRM & CDR \\
\hline $\begin{array}{l}\frac{ \pm}{ \pm} \\
\frac{\pi}{3} \\
3\end{array}$ & & & $\begin{array}{l}\text { Water is provided by The } \\
\text { Water Company. Most people } \\
\text { enjoy secure access to clean } \\
\text { water, partly because people } \\
\text { have abandoned many water- } \\
\text { scarce areas and partly } \\
\text { because The Water Company } \\
\text { supplements existing water } \\
\text { resources with wave } \\
\text { energy/desalinization/ocean } \\
\text { alkalinization projects. }\end{array}$ \\
\hline $\begin{array}{l}\frac{5}{ \pm} \\
\frac{ \pm}{\mathbb{d}} \\
\text { I }\end{array}$ & & $\begin{array}{l}\text { Al precision medicine. } \\
\text { EA \& FP: Malaria is } \\
\text { eradicated. Better distribution } \\
\text { of drugs because of } \\
\text { infrastructure from BRI. } \\
\text { SS: reemergence of disease } \\
\text { with termination shock. }\end{array}$ & $\begin{array}{l}\text { People generally live healthier } \\
\text { lifestyles and have better } \\
\text { mental health. The Rabid } \\
\text { Monkey Problem of the 2080s } \\
\text { has been brought under } \\
\text { control with vaccination } \\
\text { drones. Recreation often } \\
\text { involves interacting with } \\
\text { nature or virtual experiences. } \\
\text { sos: air pollution from fossil } \\
\text { fuels remains a problem in } \\
\text { some city-states. } \\
\text { cW: the physical and } \\
\text { psychological traumas of the } \\
\text { climate wars linger, but } \\
\text { otherwise people are living } \\
\text { healthier lives. }\end{array}$ \\
\hline 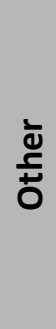 & $\begin{array}{l}\text { 3D printing, } \mathrm{Al} \text {, and } \\
\text { automation all important to } \\
\text { storylines }\end{array}$ & $\begin{array}{l}\text { Precise, near-real-time } \\
\text { satellite tracking of activities, } \\
\text { emissions anywhere on Earth. }\end{array}$ & $\begin{array}{l}\text { Social systems are highly } \\
\text { managed, and the stability of } \\
\text { the systems depends heavily } \\
\text { on a relatively small group of } \\
\text { corporate leaders' } \\
\text { commitment to } \\
\text { ecohumanism. }\end{array}$ \\
\hline
\end{tabular}




\section{Performance-based Presentations of Scenarios}

Near the end of the workshop, each group performed their stories in ways that showcased not only their visions of the future, but also how different choices at critical moments led to different futures. Each of the three groups presented their visions very differently.

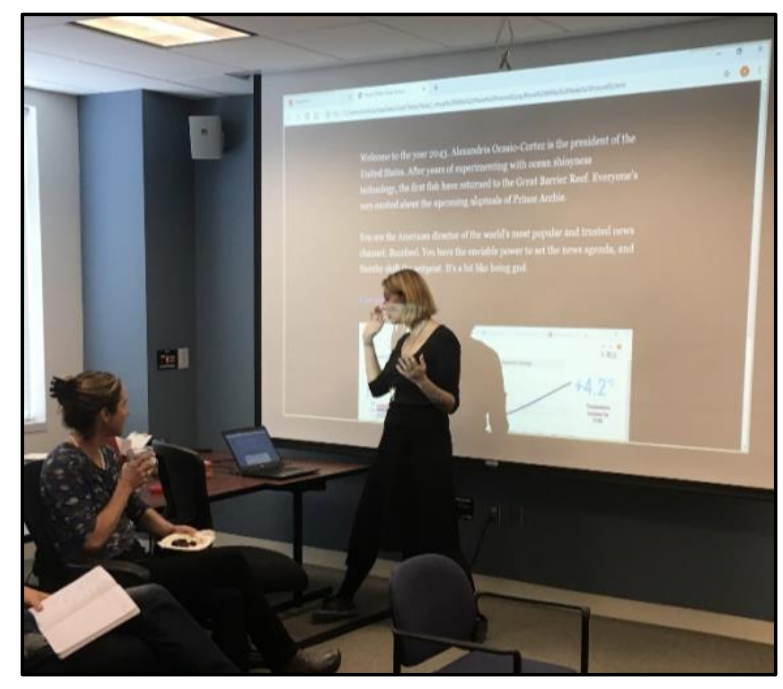

The SRM group started with a "Fortunately, Unfortunately" story (Table A3) inspired by one of the workshop ice-breakers. They then presented a series of vignettes (Fig. A3, Table A4) illustrating how different choices had led to three different futures, one of which did not even land up deploying the SRM technology.

Fig. A3: Members of the SRM group presenting one of their three contrasting futures using vignettes.
The SRM\&CDR group used the 'choose your own adventure' story they had built in Twine to lead an interactive game (Fig. A2) in which the audience was able to make decisions that led to different futures. This process informed the basis of a longer term collaboration that became the online Survive the century game: https://survivethecentury.net/.

Fig. A2: Sam Beckbessinger from the SRM\&CDR group presenting a 'choose your own adventure' story from her group using software called Twine.

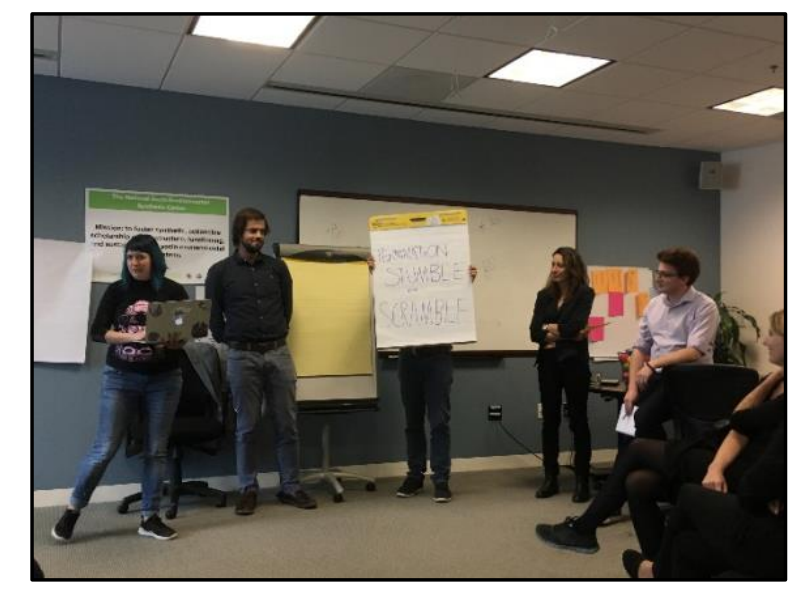


Table A3: Branching "Fortunately, Unfortunately" stories from the SRM group

\begin{tabular}{|c|c|c|}
\hline Short-term & Mid-term & Long-term \\
\hline $\begin{array}{l}\text { Unfortunately, Donald Trump } \\
\text { was re-elected in } 2020 . \\
\text { Fortunately, Expansion of Belt \& } \\
\text { Road infrastructure means more } \\
\text { economic growth and improved } \\
\text { climate adaptation across global } \\
\text { south. } \\
\text { Unfortunately, automation leads } \\
\text { to job losses \& climate change } \\
\text { to coral reef collapse in the } \\
\text { 2030s. } \\
\text { Fortunately, in response, Indo- } \\
\text { Pacific countries launch } \\
\text { Universal Basic Income and test } \\
\text { solar radiation management } \\
\text { locally. } \\
\text { Fortunately and unfortunately, } \\
\text { the social credit score becomes } \\
\text { a thing. } \\
\text { Fortunately, Al algorithms helps } \\
\text { predict weather and optimize } \\
\text { insurance and help us make } \\
\text { decisions. } \\
\text { Unfortunately, the Everything } \\
\text { Leak of } 2031 \text { means everyone is } \\
\text { doxxed. } \\
\text { Fortunately, so are } \\
\text { corporations, increasing tax } \\
\text { compliance and revenue for } \\
\text { development. }\end{array}$ & $\begin{array}{l}\text { [B] Fortunately, Belt \& Road } \\
\text { drives innovation in clean } \\
\text { energy and carbon capture. } \\
\text { Fortunately, the newly } \\
\text { empowered global south has } \\
\text { more political influence to push } \\
\text { China and the US to more rapid } \\
\text { decarbonization. } \\
\text { Adaptation is good in the } \\
\text { global south because they have } \\
\text { newer infrastructure. }\end{array}$ & $\begin{array}{l}\text { [B1] Fortunately, when } \\
\text { permafrost collapses, mitigation } \\
\text { is good enough that we don't } \\
\text { need to deploy SRM. Politically } \\
\text { high confidence in CDR. The } \\
\text { Bureau - Al machine learning } \\
\text { data and analysis helps us make } \\
\text { informed decisions. } \\
\text { Social credit score has an } \\
\text { increasing influence on people's } \\
\text { lives including their emissions } \\
\text { behaviour and controlling } \\
\text { society .... We're heading to } \\
\text { an Al-led eco-autocracy. }\end{array}$ \\
\hline
\end{tabular}


Table A4: Vignettes from the SRM group's performance

\begin{tabular}{|c|c|}
\hline Future & Vignette \\
\hline $\begin{array}{l}\text { Stumble and } \\
\text { Scramble }\end{array}$ & $\begin{array}{l}\text { My backache wakes me up. The lights don't turn on, so I imagine that the portable } \\
\text { nuclear reactor has broken down again. I guess the entire neighborhood will be } \\
\text { powerless again for two weeks. The Cornetto synthesizer doesn't work, of course. } \\
\text { Luckily my grandson downstairs still has a can of synthetic Facon and Eggs, from } \\
\text { the last military distribution of rations from last month, when war with Morocco } \\
\text { seemed inevitable over their will to deploy MBC over the Mediterranean to save } \\
\text { their fisheries. Groggy, I head over the Church of Our Cyberlady of Lovelace, to see } \\
\text { if the refugees from Madagascar need anything. On my way to the Church, I look at } \\
\text { the sky. I miss seeing birds soaring by. I miss birds. }\end{array}$ \\
\hline fAlrplay & $\begin{array}{l}\text { The response from the Al arrived yesterday. They were the longest } 2 \text { days of our } \\
\text { life. Yes, SAl can be deployed to save } 97 \% \text { of the human population and } 99 \% \text { of all } \\
\text { ecosystems, but our great country will never see rain again. I went through the } \\
\text { data the Al gave us. There seems to be no other way. Any other deployment but } \\
\text { this would save India, but kill at least } 5 \text { times more people. The first World } \\
\text { referendum will be on for another } 30 \text { hours. What do we do? Do we sacrifice our } \\
\text { country for the good of the planet? Russia has already promised to host us in their } \\
\text { new Arctic colonies. But can we trust them? The computer flashes on, reminding } \\
\text { me I haven't voted yet. My old friend from Italy has invited me to give a web-talk in } \\
\text { two hours. Quite a turn, he's had. From climate scientist to Pope. What do I tell all } \\
\text { those people in Rome? Is it okay for them to vote Yes? Are they only looking at an } \\
\text { easy way to clean their conscience? This is the land of my father, and of his father } \\
\text { before him. What would they do, in this crazy new world? }\end{array}$ \\
\hline Eco-autocracy & $\begin{array}{l}\text { Walking back from the trash mines, I feel so tired and I'd like to take a Elonmobile, } \\
\text { so I check my phone. Damn, I finished my Carbon Credits for today! I knew I should } \\
\text { have just had the locally grown beans today, but the watermelon looked so good, } \\
\text { and I forgot to check how far away it was produced. Starting tomorrow I'll be more } \\
\text { careful. XI Jinping, looking quite good for a } 150 \text { years old, has promised that } \\
\text { starting in } 2095 \text { the CO2 quotas will be raised for everyone. He even said that, by } \\
2100, \text { we'll be able to fly again, twice per year! Maybe I can finally go and visit my } \\
\text { fifth wife in the US, I haven't seen her in ages. She moved there after Mexico was } \\
\text { bombed for turning off one of their coal factories. She told me she got her gene } \\
\text { spliced and now she can see in the near infrared. That's cool, I guess. But I'm too } \\
\text { old for this shit. }\end{array}$ \\
\hline
\end{tabular}


The CDR group started with a musical, adapted from Wicked, describing the desirable future to which their narrative led (Box A1), but which alluded to the turning points in the narrative at which more problematic outcomes could have arisen.

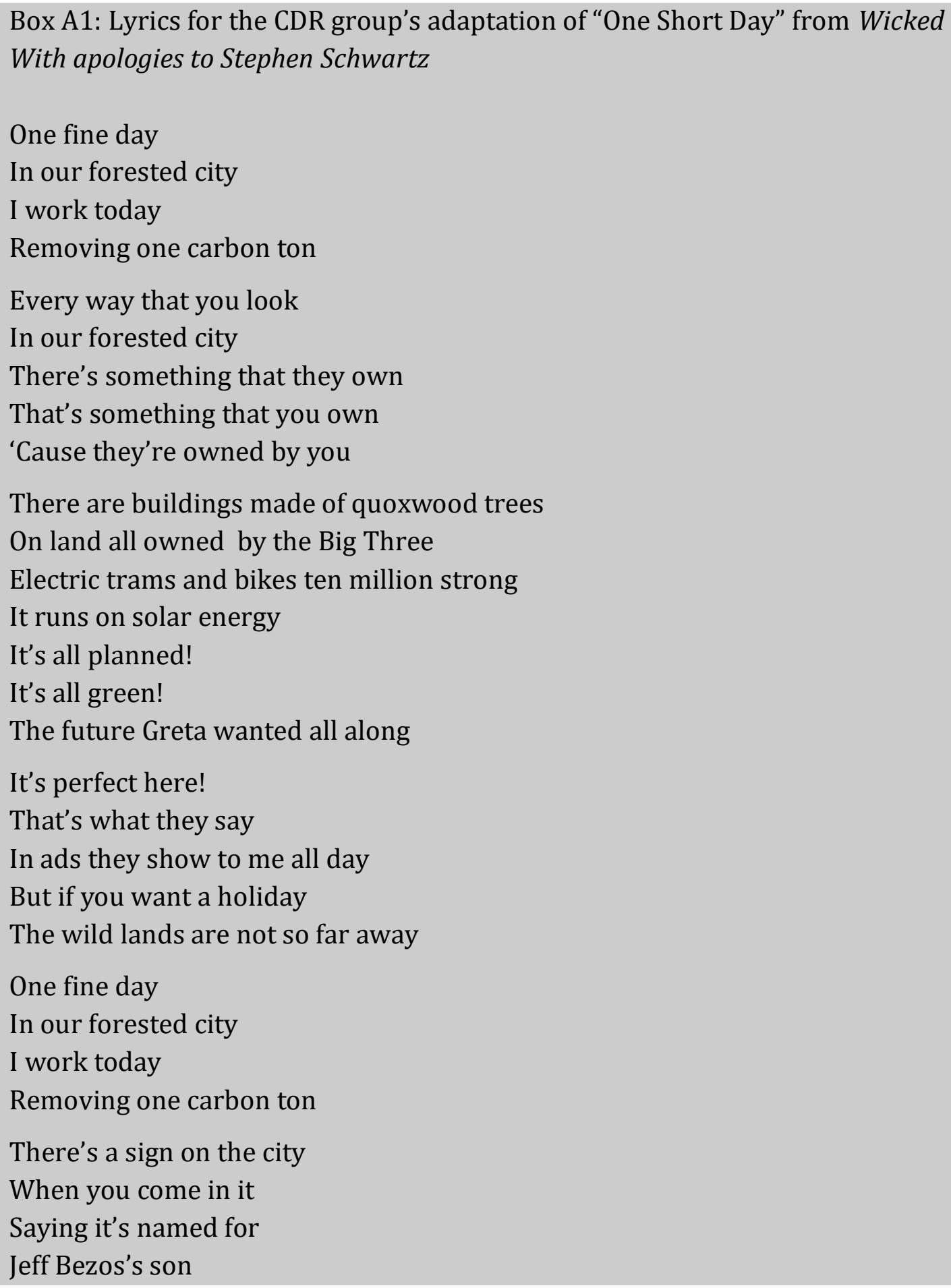




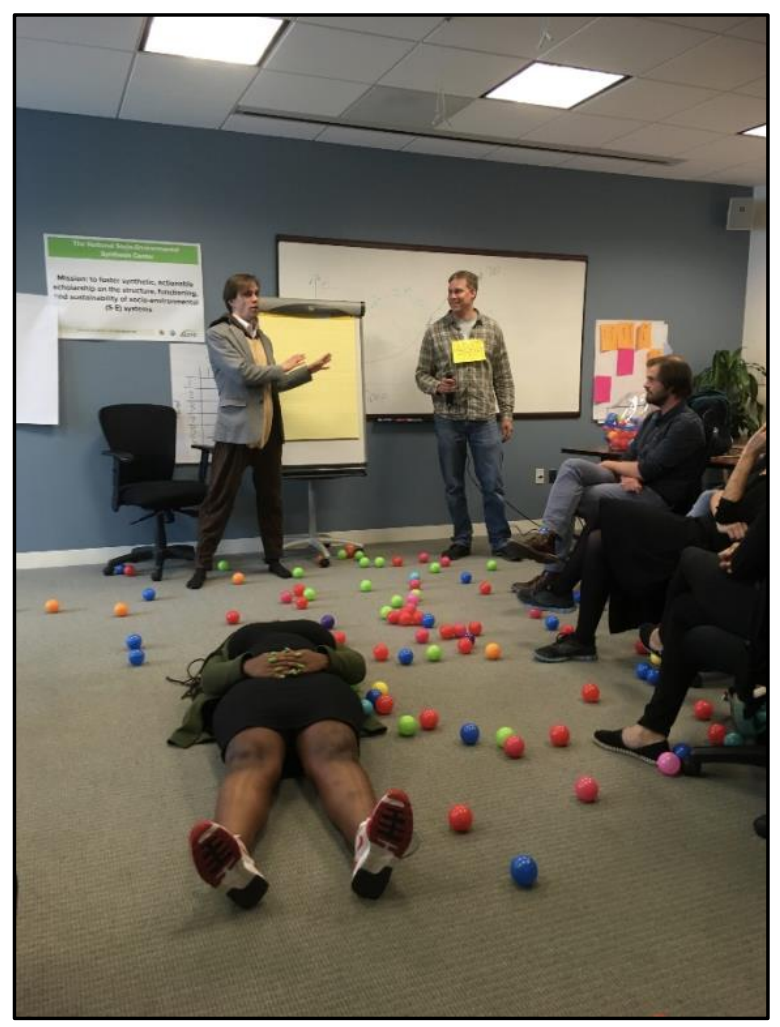

Fig. A4: The CDR group explains the skit that illustrates their scenarios. David Morrow (left, in monkey costume) gestures at David Keller (right, with electric knife), who represents the constantly encroaching threat of climate change. Mohale Mashigo (center, on floor), in the role of Dead Fish, represents the catastrophic collapse of coral reefs that plays a pivotal role in the scenarios. 